TITLE:

\title{
Mechanical performances of finger jointed cross laminated timber (CLT)
}

AUTHOR(S):

Komatsu, Kohei; Nakatani, Makoto; Nakahara, Toru; Komatsu, Kenji; Noda, Yasunobu

\section{CITATION:}

Komatsu, Kohei ...[et al]. Mechanical performances of finger jointed cross laminated timber (CLT). European Journal of Wood and Wood Products 2021, 79: 397-416

\section{ISSUE DATE:}

2021-03

URL:

http://hdl.handle.net/2433/261775

\section{RIGHT:}

This is a post-peer-review, pre-copyedit version of an article published in European Journal of Wood and Wood Products. The final authenticated version is available online at: http://dx.doi.org/10.1007/s00107-020-01645-3.; The fulltext file will be made open to the public on 4 January 2022 in accordance with publisher's 'Terms and Conditions for Self-Archiving'.; この論文は出版社版でありません。引用の際には出版社版をご確認ざ利用ください。; This is not the published version. Please cite only the published version. 


\section{European Journal of Wood and Wood Products Mechanical Performances of Finger Jointed Cross Laminated Timber (CLT) --Manuscript Draft--}

\begin{tabular}{|c|c|}
\hline Manuscript Number: & HARW-D-20-00039R1 \\
\hline Article Type: & Original Article \\
\hline Corresponding Author: & $\begin{array}{l}\text { Kohei Komatsu } \\
\text { RISH, Kyoto University } \\
\text { Uji, Kyoto Prefecture JAPAN }\end{array}$ \\
\hline Corresponding Author's Institution: & RISH, Kyoto University \\
\hline \multicolumn{2}{|l|}{$\begin{array}{l}\text { Corresponding Author's Secondary } \\
\text { Institution: }\end{array}$} \\
\hline \multirow[t]{5}{*}{ Order of Authors: } & Kohei Komatsu \\
\hline & Makoto Nakatani \\
\hline & Toru Nakahara \\
\hline & Kenji Komatsu \\
\hline & Yasunobu Noda \\
\hline \multicolumn{2}{|c|}{ Order of Authors Secondary Information: } \\
\hline Author Comments: & $\begin{array}{l}\text { Dear Editor in Chief and Reviewer } \\
\text { Thank you for your important reviews of our manuscript. Owing to your critical reviews, } \\
\text { we could aware of a lot of important mistakes. We believe they have almost corrected. } \\
\text { We hope our revised manuscript can meet your acceptance criteria. } \\
\text { Yours faithfully } \\
\text { Kohei Komatsu } \\
\text { Corresponding author }\end{array}$ \\
\hline Response to Reviewers: & $\begin{array}{l}\text { I have submitted two "word files" in the Attach Files process as the responses to the } \\
\text { Editor and reviewer. }\end{array}$ \\
\hline
\end{tabular}


Main Text revised

\title{
Mechanical Performances of Finger Jointed Cross Laminated Timber (CLT)
}

\author{
Kohei Komatsu ${ }^{1 *}$, Makoto Nakatani ${ }^{2}$, Toru Nakahara ${ }^{3}$, Kenji Komatsu ${ }^{4}$, Yasunobu Noda ${ }^{5}$
}

\author{
1: Research Institute for Sustainable Humanosphere, Kyoto University \\ 2: Miyazaki Prefectural Wood Utilization Research Center \\ 3: Kagoshima Prefectural Institute of Industrial Technology \\ 4: Yamasa Mokuzai Co. Ltd \\ 5: Forestry and Forest Products Research Institute \\ *: Corresponding author
}

\section{Abstracts}

Based on the idea of first producing small-size CLT panels and afterward connecting them using finger joints to make larger CLT panels, finger-jointed CLT test specimens were fabricated by setting experimental parameters such as the kind of finger joint (large or normal), the combination of finger joint strength (strong-strong, or weak-weak) and the number of layers, and ply (3L3P, 5L5P, and 5L7P). Destructive tests subjected to out-of-plane as well as in-plane bending and shear, and axial compression load were performed. To judge the mechanical performance of the finger-jointed CLT panels, the lower 5\% strength value evaluated from the destructive tests data were used for comparison with the characteristic strength value of CLT products assigned by the Ministry of Land, Infrastructure, Transport and Tourism in Japan (MLIT). On the other hand, the lower 50\% stiffness value evaluated from the destructive test data was used for comparison with the design stiffness values proposed by commercial sectors. Most of the tested finger-jointed CLT groups satisfied the requirements for the characteristic strength values although there were a few exceptional cases in the weak-weak groups. All of the tested finger jointed CLT groups satisfied the proposed design stiffness values.
\end{abstract}

\section{Introduction \\ 1.1 Background}

Since the first cross laminated timber (CLT) has been produced in a research project of Graz University of Technology during 1995 to 1998 (Schickhofer 2013), within about fifteen years afterward, CLT has gradually been recognized mainly among European countries as a new type of structural panel for floors or/and walls of wooden medium-rise apartment houses (e.g., Yates and Linegar 2008; Zeng et al. 2009; Bernasconi 2012). At present, CLT has been confirmed worldwide as a new era's structural wooden material having great potential (e.g., Brandner et al. 2016).

In Japan, CLT is also gathering large expectations as one of the most innovative structural materials to be used for pure CLT panel structures or hybrid structures composed of steel frames with CLT infills. As of July 2020, in Japan, there are 8 CLT production companies of which 3 companies have a potential production capacity of more than 4000 $\mathrm{m}^{3}$ per year as well as abilities of designing, processing and constructing CLT elements or/and buildings on demand from contractors, and there are already 140 CLT buildings registered in the CLT Association for promoting CLT materials and constructions (Japan CLT Association 2020).

\subsection{Research Purposes}

\subsubsection{Aim for producing finger-jointed CLT panels}

Except for the Japanese largest CLT company which has sufficient producing facilities for large-size CLT panels (max. $12 \mathrm{~m}$ in length and $3 \mathrm{~m}$ in width), the rest of CLT companies in Japan are still producing relatively 
Main Text revised

small-size CLT panels of $4 \mathrm{~m}$ to $8 \mathrm{~m}$ in length and $1.2 \mathrm{~m}$ to $3 \mathrm{~m}$ in width (Japan CLT Association 2020) using relatively small-scale production systems, mainly due to the balance among the demand, the supply and facility costs. If there is a need to produce large CLT panels, following two alternative methods might be possible. One is to first join small CLT panels in a factory and afterward transport the expanded panels to the construction site. The other is to first transport small CLT panels to the construction site and afterward join them on-site. To realize these two alternative ideas, it is necessary to evaluate the mechanical performance of finger-jointed CLT panels experimentally, although one European company has already tried to confirm this possibility (Brandner 2013) and CLT panels expanded by the LF joints have been approved as "cross laminated timber (X-Lam) with large finger joints" in Europe (EN 16351 2015).

Connecting glued laminated timber (GLT) using LF joints in factories has been executed in Germany for assembling GLT frame corner joints (e.g., Aicher et al. 1997). The authors have also evaluated strength properties of GLT frame corner joints composed of various LF joints (Komatsu et al. 2001). In the case of finger joints of CLT, however, as more sophisticated joint combinations and fracture phenomena than those of GLT-GLT are to be expected (Blaß and Flaig 2015), it was required to execute fundamental destructive tests by setting various experimental parameters such as the kind of a finger joint, the combination of finger joint strength, and the number of layers and ply.

\subsubsection{Evaluation policy on the experimental results and the control test data}

The most important purpose of this research is to confirm whether the finger-jointed CLT panels could be used as structural components of CLT buildings. At present in Japan, to use CLT for pure CLT buildings or hybrid buildings composed of steel frames with CLT infills, all CLT components must show that their mechanical performance is beyond or at least at the same level of the characteristic values determined in the Notification \#1324 issued by the Ministry of Land, Infrastructure and Tourism of Japan (MLIT 2018). The evaluation method using the non-finger jointed control specimen is considered as a simple and clearer method in order to relatively know the joint performance. In this research, however, all experiments except compression tests were executed without preparing control specimens to evaluate the lower tolerance limit values for comparison with the characteristic values given in the notification (MLIT 2018).

After all experiments were completed, however, it was found that the company which supplied CLT for this research had already performed in-plane and out-of-plane bending tests on CLT panels. The test specimens used in these experiments were not only non-finger-jointed, but were also composed of laminae of the same species, same size, and same layups as those used in this study and the test conditions were nearly the same. Therefore, it is supposed that these separate experimental results can be used as the reference data to estimate the apparent strength and stiffness ratios of the finger-jointed CLT panels subjected to the in-plane and the out-of-plane bending.

\section{Experiments}

\subsection{Materials}

In this research, three different layups of CLT panels shown in Fig.1 were used. These CLT panels were fabricated in a Japanese CLT production company which holds the production approval according to the JAS-3079 (MAFF 2013). Species of laminae were all Japanese cedar (Cryptomeria japonica D. Don).

\section{Fig.1 JAS definitions of CLT and descriptions of finger-jointed CLT specimens}

In the JAS definitions of CLT shown in Fig.1, " $n$-Layer" means the number of strong or weak axis layers, while " $m$-Ply" means the number of laminae composing a CLT panel. The CLT panel used in this experiment was composed of M60 laminae with MOE of more than $6 \mathrm{kN} / \mathrm{mm}^{2}$ in the outer layer and of M30 laminae with MOE of more than $3 \mathrm{kN} / \mathrm{mm}^{2}$ in the inner layer as shown in Fig.1, respectively. It is said that the reason why Japanese 
Main Text revised

cedar's MOE is relatively lower is that this species is a fast-growing softwood tree grown in plantations.

The most distinctive feature of the CLT panels used in this research is that all laminae are preliminarily glued to each other along the narrow edge surfaces (using aqueous vinyl polymer solution isocyanate adhesive: API). The density of the CLT produced was on average $423 \mathrm{~kg} / \mathrm{m}^{3}$ with the standard deviation of $23 \mathrm{~kg} / \mathrm{m}^{3}$, and the moisture content was on average $11.2 \%$ with the standard deviation of $1.1 \%$. This relatively higher density value compared with solid sawn Japanese cedar (e.g., $\rho=350-380 \mathrm{~kg} / \mathrm{m}^{3}$, Anshari et al. 2011) seems to be affected by the additional weight of glue-lines from both edge-gluing and laminating-gluing using API.

\subsection{Finger joints used for CLT connections}

\subsubsection{Finger profiles}

In this study, NF joint having a $24 \mathrm{~mm}$ nominal finger length and LF joint having a $50 \mathrm{~mm}$ nominal finger length were used. The finger-cutting profiles on the CLT specimens were observed which were prepared for determining the appropriate end-pressure to be described in the next section 2.2.2. The details of these two finger-cutting profiles on the CLT are shown in Online Resources- 1 .

\subsubsection{Determination of the appropriate push-in pressure and finger jointing procedure}

In Japan, the push-in pressure used in the industrial finger joints has been determined empirically as the stress value closer to the lower limit stress which could be observed from the push-in experiment using a pair of pre-cured finger jointed specimens (e.g., Horie and Kurata 1984). In this experiment, the appropriate push-in pressure for CLT specimen was also determined as $1 \mathrm{~N} / \mathrm{mm}^{2}$ following the previous Japanese domestic research (Noda et al. 2013) by paying attention to the possibilities of the on-site gluing condition (Japan HOWTEC, 1992). The quantity of $1 \mathrm{~N} / \mathrm{mm}^{2}$ as the push-in pressure for CLT panels seems to be a relatively high value compared with the approved minimum value of $0.3 \mathrm{~N} / \mathrm{mm}^{2}$ given in the Annex-I6 of the European standard for the CLT (EN 16351 2015).

The details of the determination of the appropriate push-in pressure are given in Online Resource-2. All test specimens were made at the push-in pressure value of $1 \mathrm{~N} / \mathrm{mm}^{2}$ using a temporary finger jointing device shown in Online Resource-3.

\subsection{Bending Tests}

\subsubsection{Test setups}

Fig.2 Setups for the bending test on the finger jointed CLT specimens

Figure 2 shows the setups for the bending test on the finger jointed CLT specimens. These setups were designed according to the Japanese domestic manual for testing structural wooden materials (Japan HOWTEC 2011). This domestic manual is said to have been compiled based on an old ISO standard (ISO 13910 2005), which also referred to the North American standards (ASTM D1990-00 2002; ASTM D2915-03 2003; ASTM D198-05a 2005a; ASTM D4761-05 2005b) and the European standards (EN 4081995; EN 308 2004).

In Europe, the reference cross-section of a CLT panel is said to be $150 \mathrm{~mm} \times 600 \mathrm{~mm}$ (Brandner et al. 2016). While in Japan, as the value of a $300 \mathrm{~mm}$ was used for the width of CLT out-of-plane bending test specimens in the past national-scale research project (FFPRI 2015), the $300 \mathrm{~mm}$ for the width of the out-of-plane CLT bending specimen was also adopted to harmonize with previous national-scale experiments.

As there were not enough finger cutters available for large finger joints (LFJ), 5Layers-7Plys specimens $(d=210 \mathrm{~mm}$ ) could not be prepared in the group of LFJ in this study. Therefore, specimens connected by LFJ were 4 groups, while specimens connected by normal finger joint (NFJ) were always 6 groups. In the case of in-plane bending test, the depth of beam $d$ was fixed to be a total width of two laminae $(d=2 \times b l=2 \times 120=240 \mathrm{~mm})$ to meet the condition that the maximum specimen length available was about $4 \mathrm{~m}$ and the span/depth ratio $(d / L)$ should be at 


\section{Main Text revised}

least 15 (Japan HOWTEC 2011). This in-plane bending specification with beam depth equivalent to two laminae widths is, by chance, similar to that assigned in the Annex-F of the European CLT standard (EN 16351 2015). Table 1 shows the specification of all test specimens.

\section{Table 1 Specification of the test specimens}

\subsubsection{Evaluation of the modulus of rupture (MoR) and modulus of elasticity (MoE)}

MoR of finger jointed CLT panel $f_{m}$ and apparent MoE of finger jointed CLT panel $E_{m}$ were evaluated using Equations (1) and (2), which were defined in the Japanese domestic manual (Japan HOWTEC 2011).

$$
\begin{aligned}
& f_{m}=\frac{a \cdot F_{u l t}}{2 Z_{0}} \ldots . .(1) \\
& E_{m}=\frac{a \cdot\left(3 L^{2}-4 a^{2}\right)\left(F_{2}-F_{1}\right)}{48 I_{0}\left(\delta_{2}-\delta_{1}\right)} \ldots . .(2)(\text { the effect of shear deflection is included) }
\end{aligned}
$$

where

a: Shear span length (mm), refer to Fig.2-(a) and (c)

$L$ : Total span length (mm), refer to Fig.2-(a) and (c)

$F_{\text {ult: }}$ Ultimate applied load (N), refer to Fig.2-(a) and (c)

$F_{1}: 10 \%$ value of $F_{\text {ult }}(\mathrm{N})$

$F_{2}: 40 \%$ value of $F_{\text {ult }}(\mathrm{N})$

$\delta_{1}$ : Midspan deflection corresponding to $F_{1}(\mathrm{~mm})$

$\delta_{2}:$ Midspan deflection corresponding to $F_{2}(\mathrm{~mm})$

$Z_{0}$ : Section modulus of CLT panel $=b d^{2} / 6\left(\mathrm{~mm}^{3}\right)$, refer to Fig.2-(a) and (c)

$I_{0}$ : The second moment of area of the CLT panel $=b d^{3} / 12\left(\mathrm{~mm}^{4}\right)$, refer to Fig.2-(a) and (c)

\subsubsection{Characteristic MoR and design MoE of the specimens subjected to the out-of-plane bending}

According to the Notification \#1324 (MLIT 2018), the characteristic MoR of CLT panel $F_{b_{-} \text {out }}$ subjected to the out-of-plane bending shall be estimated by Equation (3).

$$
\left.\begin{array}{l}
F_{b_{-} \text {out }}=\sigma_{b-\text { oml }} \cdot \frac{I_{A}}{I_{0}} \times 0.4875 \\
I_{A}=\frac{\sum\left(E_{i} \cdot I_{i}+E_{i} \cdot A_{i} \cdot z_{i}^{2}\right)}{E_{0}}
\end{array}\right\}
$$

The design MoE of CLT panel $E_{b_{-} \text {out }}$ subjected to the out-of-plane bending shall be estimated by Equation (4) (Japan HOWTEC \& Japan CLT Association 2016).

$$
E_{b-\text { out }}=\frac{\sum\left(E_{i} \cdot I_{i}+E_{i} \cdot A_{i} \cdot z_{i}^{2}\right)}{I_{0}} \ldots
$$

where,

$\sigma_{b-o m l}$ : The bending strength of the outer ply when calculating the characteristic value in the strong axial direction, and that of the inner ply closest to the outer ply when calculating the characteristic value in the weak axial direction. The actual values used in this research were $\sigma_{b-o m l}=27 \mathrm{~N} / \mathrm{mm}^{2}$ for the outer ply strong axis (M60) and $\sigma_{b-o m l}=19.5 \mathrm{~N} / \mathrm{mm}^{2}$ for the inner ply strong axis (M30), respectively.

$A_{i}$ : Cross section of the $\mathrm{i}^{\text {th }}$ ply $\left(\mathrm{mm}^{2}\right)$ 


\section{Main Text revised}

$E_{i}$ : Modulus of elasticity of the $\mathrm{i}^{\text {th }}$ ply. ( $E_{i}=0$ for the transversal ply)

$E_{0}$ : Modulus of elasticity of the outer ply when calculating the value in the strong axial direction, and that of the inner ply closest to the outer ply when calculating the value in the weak axial direction. The actual values used in this research were $E_{0}=6 \mathrm{kN} / \mathrm{mm}^{2}$ for the outer ply (M60) strong axis, $E_{0}=3 \mathrm{kN} / \mathrm{mm}^{2}$ for inner ply (M30) strong axis, respectively.

$I_{i}$ : The second moment of area of the $\mathrm{i}^{\text {th }}$ ply $\left(\mathrm{mm}^{4}\right)$

$I_{0}$ : The second moment of area of the CLT panel $\left(\mathrm{mm}^{4}\right)$

$z_{i}$ : Distance between the center of gravity of $\mathrm{i}^{\text {th }}$ ply and the neutral axis of the CLT panel $(\mathrm{mm})$

$d:$ Height of CLT panel (mm)

$b$ : Width of CLT panel (mm)

0.4875: Composite adjustment factor $=0.75$ (adjustment factor based on the lower $5^{\text {th }}$ percentile value) times 0.65 (another adjustment factor)

\subsubsection{Characteristic MoR and design MoE of the specimens subjected to the in-plane bending}

The characteristic MoR of CLT panel $F_{b \_ \text {in }}$ subjected to the in-plane bending shall be estimated by equation (5) (MLIT 2018).

$$
\left.\begin{array}{c}
F_{b_{-} \text {in }}=\sigma_{b-o m l} \cdot \frac{A_{A}}{A_{0}} \times 0.6 \\
A_{A}=\frac{\sum\left(E_{i} \cdot A_{i}\right)}{E_{0}} \\
A_{0}=b \cdot d
\end{array}\right\} \ldots . .(5)
$$

The MoE of CLT panel $E_{b \_ \text {in }}$ subjected to the in-plane bending shall be estimated by equation (6) (Japan HOWTEC \& Japan CLT Association 2016).

$$
E_{b_{-} i n}=\frac{\sum\left(E_{i} \cdot A_{i}\right)}{A_{0}}
$$

where,

0.6: Composite adjustment factor $=0.75$ (adjustment factor based on the lower $5^{\text {th }}$ percentile value) times 0.8 (another adjustment factor)

\subsection{Shear Test}

\subsubsection{Setups}

\section{Fig.3 Setups for the shear test on the finger jointed CLT specimens}

Figure 3 shows the setups for the shear test on the finger jointed CLT specimens. The anti-symmetrical four-point loading shear test method shown in Figs.3-(a) and (b) is accepted as an alternative for evaluating shear properties of structural timber beam (Japan HOWTEC 2011). In this test configuration, the zero moment point coincides with the center of a constantly high shear force region, therefore, there is a high likelihood of shear failure compared with the three-point loading shear test (ISO 13910 2014; Japan HOWTEC 2011) or the four-point loading shear test (EN 16351 2015), both of which have higher possibility of preceding bending failures. Besides, as the joint part can be centered in a constantly high shear force region, this method seems to be suitable for evaluating the shear strength of any kind of joint specimens.

In the case of in-plane shear test, side plane of the specimen was determined to make glue-lines of the edge-gluing intentionally located as far as possible from the center of the beam depth $d$ which was fixed to the two 
Main Text revised

laminae $\left(d=2 \times b_{l}=240 \mathrm{~mm}\right)$, as shown in Fig.3-(a). While in the case of the out-of-plane shear test, the three-point loading shear test method shown in Figs.3-(c) and (d), which is recommended in ISO 13910 (2014) and JAS standard (MAFF 2013) for evaluating shear properties of CLT, was used for getting shear strength without measuring shear strains.

\subsubsection{Evaluation of the shear strength and the shear rigidity of the specimens subjected to in-plane shear}

In Fig.3-(a), forces at loading points and supporting points $F_{a}, F_{b}$, and shear force $Q$ in the constant shear force region $S$ are given in Equations (7), (8) and (9).

$$
\begin{aligned}
& F_{a}=\frac{(2 a+S) \cdot F}{2(a+S)} \\
& F_{b}=\frac{S \cdot F}{2(a+S)} \\
& Q=F_{b}-F_{a}=\frac{a \cdot F}{(a+S)} \ldots
\end{aligned}
$$

In the case of evaluating shear strength of beam based on the elementary beam theory, the effect of span/depth ratio on the shear stress distribution must be taken into consideration (here, span means a distance between loading point and supporting point). Brandner et al. (2012) pointed out, based on their FEM analyses, that if the span/depth ratio of timber beam is less than 3 , the intensity of shear stress along the depth direction is less than $65 \%$ of that given by the elementary beam theory in which the maximum shear stress is 1.5 time of the average shear stress. Therefore, in the case of the anti-symmetrical four-point loading specimen used in this research, as the quantities of $S / d$ and $a / d$ are 1.5 to 2.0 (see Table 1 and Fig.3-a)), the value of the maximum shear stress at the constant shear force zone $S$ will be less than $65 \%$ of that given by the elementary beam theory. Hence, it is assumed that the maximum shear stress at mid-depth in constant shear force zone $S$ was less than $65 \%$, namely $\tau_{S}=\tau_{\text {avg }} \times 1.5 \times 0.65=0.975 \times \tau_{\text {avg }} \approx$ $\tau_{\text {avg }}$ was assumed. Consequently, the shear strength of the specimen $f_{\mathrm{s} \_ \text {in }}$ in equation (10-b) is evaluated by substituting the ultimate applied load $F_{\text {ult }}$ into Equation (10-a).

$$
\begin{aligned}
& \tau_{S} \approx \tau_{\text {avg }}=\frac{Q}{A}=\frac{a \cdot F}{A(a+S)} \ldots \ldots(10-a) \\
& f_{S_{\text {_in }}} \approx \frac{a \cdot F_{u l t}}{A \cdot(a+S)} \ldots \ldots \ldots \ldots \ldots(10-b)
\end{aligned}
$$

where

$A=b \cdot d \quad$ : Cross-sectional area of the beam $\left(\mathrm{mm}^{2}\right)$

$F_{u l t}$ : Ultimate applied load (N)

Shear strain at the mid-depth of the beam is evaluated in Equation (11) using strain values observed by the Rosset gauge $(R G)$ put on both sides of the $F J$ line as shown in Fig.3-(a).

$\gamma_{S}=2 \varepsilon_{45}-\left(\varepsilon_{0}+\varepsilon_{90}\right)$...

Finally, the shear rigidity of the finger jointed CLT panel $G_{S_{-} i n}$ is evaluated in Eq. (12).

$$
G_{S_{-} i n}=\frac{\left(\tau_{S 2}-\tau_{S 1}\right)}{\left(\gamma_{S 2}-\gamma_{S 1}\right)}
$$

where,

$\tau_{s 1}$ : shear stress estimated as $10 \%$ of the maximum shear stress value $\left(\mathrm{N} / \mathrm{mm}^{2}\right)$

$\tau_{s 2}$ : shear stress estimated as $40 \%$ of the maximum shear stress value $\left(\mathrm{N} / \mathrm{mm}^{2}\right)$

$\gamma_{S 1}$ : shear strain measured at $10 \%$ of the maximum force

$\gamma_{S 2}$ : shear strain measured at $40 \%$ of the maximum force 
Main Text revised

\subsubsection{Evaluation of the shear strength for the specimens subjected to out-of-plane shear}

The shear strength of the finger jointed CLT panel $f_{s_{-} \text {out }}$ subjected to the out-of-plane shear force is evaluated in Equation (13) (ISO 13910 2014; Japan HOWTEC 2011).

$f_{s_{-} \text {out }}=\frac{3 \cdot F_{u l t}}{4 A} \ldots$

where

$A=b \cdot d \quad$ : Cross-sectional area of the finger-jointed specimen $\left(\mathrm{mm}^{2}\right)$

$F_{\text {ult }}$ : Ultimate applied load (N)

\subsubsection{Characteristic shear strength and design shear rigidity of the specimens subjected to the in-plane shear}

The characteristic shear strength of CLT panel $F_{S_{-} i n}$ subjected to the in-plane shear force shall be estimated by equation (14) (MLIT 2018).

$$
F_{s_{-} \text {in }}=\min \left\{\begin{array}{c}
f_{v_{-} \text {lam_o }} \\
f_{v_{-} \text {lam }} \text { 90 } \frac{t_{\text {net }}}{t_{\text {gross }}} \\
\left.\frac{3 \cdot b_{\text {lam }} \cdot n_{\text {ca }}}{8 \cdot t_{\text {gross }} \cdot\left\{\frac{1}{f_{v_{-} \text {tor }}}\left(1-\frac{1}{m^{2}}\right)+\frac{2}{f_{R}}\left(\frac{1}{m}-\frac{1}{m^{2}}\right)\right.}\right\}
\end{array}\right\} \ldots(14)
$$

Equation (14) is based on the original proposal by Flaig and Blass (2013). In the third equation in Equation (14), however, a value of $3 / 4$ that indicates the coefficient of variation associated with the lower $5 \%$ strength value was multiplied by the original third equation proposed by Flaig and Blass (2013).

where,

$f_{v_{-} l a m_{-} 0}:$ Shear strength of lamina parallel to the grain $\left(2.7\right.$ for Japanese cedar) $\left(\mathrm{N} / \mathrm{mm}^{2}\right)$

$f_{v_{-} l a m_{-} 90}:$ Shear strength of lamina perpendicular to the grain $\left(8.1\right.$ for Japanese cedar) $\left(\mathrm{N} / \mathrm{mm}^{2}\right)$

$f_{v_{-} \text {tor }}$ : Torsional strength of two cross bonded laminae (3.0 for Japanese cedar) $\left(\mathrm{N} / \mathrm{mm}^{2}\right)$

$f_{R}$ : Rolling shear strength of lamina (1.5 for Japanese cedar) $\left(\mathrm{N} / \mathrm{mm}^{2}\right)$

$b_{\text {lam }}:$ Width of the single lamina $(\mathrm{mm})$

$t_{\text {gross }}:$ Width of CLT panel (mm)

$t_{n e t}:$ Sum of the thickness of transversal layers (mm)

$n_{c a}:$ Number of glued surfaces in the width direction

$m$ : Minimum number of laminae in the depth direction

The shear rigidity of CLT panel $G_{s \_ \text {in }}$ subjected to the in-plane shear force shall be given by Equation (15) common to all types of CLT (Japan HOWTEC \& Japan CLT Association 2016).

$$
G_{S_{-} i n}=0.5 \mathrm{kN} / \mathrm{mm}^{2}
$$

\subsubsection{Characteristic shear strength of the specimens subjected to the out-of-plane shear}

The characteristic shear strength of CLT panel $F_{S_{-} \text {out }}$ subjected to the out-of-plane shear force shall be given by Equation (16) common to all types of CLT (MLIT 2018).

$$
F_{s_{-} \text {out }}=0.9 \ldots(16) \quad\left(\mathrm{N} / \mathrm{mm}^{2}\right)
$$


Main Text revised

\subsection{Compression Parallel to the Grain Test}

\subsubsection{Test set-up}

\section{Fig.4 Setup for the compression test on the finger jointed CLT specimens}

Figure 4 shows the test setup for the finger-jointed CLT specimens subjected to the compression force. Experiments were carried out using a specific compression-testing machine having a maximum loading capacity of $2000 \mathrm{kN}$ as shown in Fig.4-(b). Apparent compressive deformation was measured using a pair of deformation meters (CDP-50, 50mm capacity), having a 360mm target length $(l)$ and $F J$ (finger joint) allocated at the mid-point of the target length.

\subsubsection{Evaluation of the strength and modulus of elasticity for the specimens subjected to compression force}

The compression strength of the finger jointed CLT specimen $f_{c}$ is estimated in equation (17).

$f_{c}=\frac{F_{u l t}}{A}$

where

$A=b \cdot d$ : Cross-sectional area of the finger-jointed specimen $\left(\mathrm{mm}^{2}\right)$

$F_{\text {ult }}$ : Ultimate applied load (N)

The modulus of elasticity of the finger-jointed CLT panel $E_{\mathrm{c}}$ subjected to axial compression force is evaluated in equation (18)

$E_{c}=\frac{l \cdot\left(F_{2}-F_{1}\right)}{A\left(w_{2}-w_{1}\right)}$

where,

$F_{1}$ : Compression force estimated as $10 \%$ of the maximum compression force $(\mathrm{N})$

$F_{2}$ : Compression force estimated as $40 \%$ of the maximum compression force $(\mathrm{N})$

$w_{1}$ : Compression deformation measured at $10 \%$ of the maximum force $(\mathrm{mm})$

$w_{2}$ : Compression deformation measured at $40 \%$ of the maximum force (mm)

$l$ : Target length $(360 \mathrm{~mm})$

$A=b \cdot d \quad$ : Cross-sectional area of the finger jointed specimen $\left(\mathrm{mm}^{2}\right)$

\subsubsection{Characteristic compression strength and modulus of elasticity}

The characteristic compression strength of CLT panel $F_{c}$ subjected to the axial compression force shall be estimated by equation (19) (MLIT 2018).

$$
\left.\begin{array}{c}
F_{c}=\sigma_{c-o m l} \cdot \frac{A_{A}}{A_{0}} \times 0.75 \times \eta \\
A_{A}=\frac{\sum\left(E_{i} \cdot A_{i}\right)}{E_{0}} \\
A_{0}=b \cdot d
\end{array}\right\}
$$

where

$\sigma_{c-\text { oml }}$ : The compression strength of the outer ply when calculating the characteristic value in the strong axial direction, and that of the inner ply closest to the outer ply when calculating the characteristic value in the weak axial direction. The actual values used in this research were $\sigma_{c-o m l}=21.6 \mathrm{~N} / \mathrm{mm}^{2}$ for the outer ply strong axis (M60) and $\sigma_{c-o m l}=15.6 \mathrm{~N} / \mathrm{mm}^{2}$ for the inner ply strong axis (M30), respectively (N/mm²).

0.75: Adjustment factor based on the lower $5^{\text {th }}$ percentile value

$\eta$ : "Decreasing factor due to buckling" estimated by equation (20) 
Main Text revised

$$
\left.\begin{array}{cr}
\eta=1 & 30 \geq \lambda \\
\eta=1.3-0.01 \cdot \lambda & 30<\lambda \leq 100 \\
\eta=\frac{3000}{\lambda^{2}} & 100<\lambda
\end{array}\right\} \ldots(20)
$$

$\lambda:$ "Effective slenderness ratio" estimated by equation (21)

$$
\lambda=L_{e f f} \cdot \sqrt{\frac{A_{e f f}}{I_{e f f}}} \ldots
$$

As the specific compression-testing machine had the pin-jointed loading head and non-rotating lower support composed of the flat-bar as can be seen in Fig.4-(b), effective buckling length $L_{\text {eff }}$ was determined as $70 \%$ of the real column length following the guidance of the standard (AIJ Standard 2006).

$L_{\text {eff }}$ : Effective buckling length $(=0.7 \times L=623 \mathrm{~mm}), L=890 \mathrm{~mm}$

$A_{\text {eff: }}$ Effective cross-sectional area. In the case of the strong axial direction, the whole area shall be taken. In the case of the weak axial direction, outer ply shall be neglected $\left(\mathrm{mm}^{2}\right)$ (MLIT 2018).

$I_{\text {eff: }}$ Effective second moment of area. In the case of the strong axial direction, the whole section shall be taken. In the case of the weak axial direction, outer ply shall be neglected ( $\mathrm{mm}^{4}$ ) (MLIT 2018).

The modulus of elasticity of CLT panel $E_{c}$ subjected to the axial compression force shall be estimated by equation (22) (Japan HOWTEC \& Japan CLT Association 2016).

$$
E_{c}=\frac{\sum\left(E_{i} \cdot A_{i}\right)}{A_{0}} \ldots
$$

\section{Results and Discussion}

\subsection{Evaluation of the Experimental Data and Comparison with the Estimated Values}

Since the main purpose of this study is to confirm whether the finger-jointed CLT panels could be used as the structural components of CLT buildings, the lower 5\% strength values at the $75 \%$ confidence level (hereafter denoted as the lower $5 \%$ strength value $f_{-55 \%}$ ) obtained in the destructive experiments are compared with the characteristic strength values determined in the Notification \#1324 (MLIT 2018).

On the other hand, the lower $50 \%$ stiffness values at the $75 \%$ confidence level (hereafter denoted as the lower $50 \%$ stiffness value $E_{-50 \%}$ or $G_{-50 \%}$ ) obtained in the destructive experiments are compared with the design stiffness values proposed by Japan HOWTEC and Japan CLT Association (2016).

Although the log-normal distribution is assumed in the European standard (EN 14358 2006), $f_{05} \%$ is evaluated by equation (23) and $E_{-} 50 \%$ or $G_{-50 \%}$ by equation (24) according to AIJ Standard (2006) based on the assumption of the normal distribution (ASTM D2915-03 2003).

$$
\begin{aligned}
f_{-05 \%} & =X-K_{-05 \%} \times \text { S. D. ....(23) } \\
E_{-50 \%} \text { or } G_{-50 \%} & =X-K_{-50 \%} \times \text { S. D. ....(24) }
\end{aligned}
$$

where,

$X$ : Mean value

S.D.: Sample standard deviation

$K_{-05 \%}=2.336$ in the case of a sample size of six (ASTM D2915-03 2003; AIJ Standard 2006)

$K_{-50 \%}=0.297$ in the case of a sample size of six (AIJ Standard 2006)

\subsection{Out-of-Plane Bending}

Figure 5 shows the load $(P)$ - midspan deflection $(\delta)$ relationships and typical failure phenomena observed from 


\section{Main Text revised}

the out-of-plane bending test.

Figure $5 P-\delta$ relationships and typical failure phenomena of finger jointed CLT specimens subjected to out-of-plane bending moment.

Table 2 shows the results of the out-of-plane bending test. In Table $2, F_{b_{-} \text {out }}$ indicates the characteristic MoR of CLT panel estimated by equation (3) that was given in the Notification \#1324 (MLIT 2018) and $E_{b_{-} \text {out }}$ indicates the design MoE estimated by equation (4) (Japan HOWTEC \& Japan CLT Association 2016). On the other hand, $f_{m_{-} \text {out_avg }}, f_{m_{-} \text {out_o5\% }}$ indicate the average strength value and the lower $5 \%$ strength value, and $E_{m_{-} \text {out_avg }}$, $E_{m_{\_} \text {out }} 50 \%$ indicate the average stiffness value and the lower $50 \%$ stiffness value, all are evaluated from six experimental data in each specimen group. The specimen groups marked with “*1" represent non-finger-jointed CLT panels (controls) (ANON 2016).

\section{Table 2 Results of the Out-of-Plane Bending Test}

From Fig. 5 and Table 2 it can be seen, specimens jointed by LF joint tended to be slightly stronger than those jointed by NF joint. The ratios $f_{m_{-} \text {out_ } 05 \%} / F_{b_{-} \text {out }}$ of all finger-jointed specimen groups showed higher values than 1.0. This indicates that the finger-jointed CLT panels met the requirement for the characteristic out-of-plane bending strength assigned to the non-finger jointed CLT panels (MLIT 2018). The ratios in the W-W groups, however, showed higher values of 3.56 to 9.93 . There might be two reasons. One reason is that the laminae used in this study were all edge-glued preliminary in the factory so that the tensile strength of the weak-layer was not zero but having at least the value close to the strength perpendicular to the grain. Another reason is that the current estimation equation (3) given by the Notification \#1324 assumes all performances in the weak axial direction to be zero. As a result, these two factors have led to overestimation of characteristic values on the safe side in the case of the W-W group.

From Table 2, for the out-of-plane bending MoE, the difference between the LF joint and the NF joint was not clear. The ratios $E_{m_{-} \text {out } 50 \%} / E_{b_{-} \text {out }}$ showed reasonable values of 1.03 to 1.27 in the S-S groups. On the other hand, the ratios in the W-W groups showed higher values of 2.73 to 4.99 . These higher ratios are also affected by the two factors mentioned above.

The apparent strength and stiffness ratios of the strong-strong CLT specimens showed reasonable values of 0.66 to 0.82 , and 0.86 to 0.99 , respectively. On the other hand, those of the weak-weak CLT specimens showed unusual values of 0.87 to 1.19 , and 1.15 to 1.23 , respectively. Strength and stiffness of timber perpendicular to the grain are inherently "unstable" and "scatter" therefore the common sense found in the usual finger joints parallel to the grain may not hold. In the case of the out-of-plane bending, it is confirmed that the LF jointed CLT specimens show a better strength performance than NF jointed CLT specimens.

\subsection{In-Plane Bending}

Figure 6 shows the load $(P)$ - midspan deflection $(\delta)$ relationships and typical failure phenomena observed from the in-plane bending test.

Fig.6 $P-\delta$ relationships and typical failure phenomena of finger jointed CLT specimens
subjected to in-plane bending moment.

Table 3 shows the results of the in-plane bending test. In Table $3, F_{b}$ in indicates the characteristic MoR of CLT panel estimated by equation (5) that was given in the Notification \#1324 (MLIT 2018) and $E_{b_{-} \text {in }}$ indicates the design MoE estimated by equation (6) (Japan HOWTEC \& Japan CLT Association 2016). On the other hand, $f_{m \_i n \_a v g}, f_{m_{-} i n_{-} 05 \%}$ indicate the average strength value and the lower $5 \%$ strength value, and $E_{m_{-} i n_{-} a v g}$, $E_{m_{-} \_ \text {in_50\% }}$ indicate the average stiffness value and the lower 50\% stiffness value, all are evaluated from six experimental data in each specimen group. The specimen groups marked with " **1" represent non-finger-jointed CLT panels (controls) (ANON 2016). 
Main Text revised

From Fig.6 and Table 3 it can be seen that the differences in the performance between the specimens jointed by $\mathrm{NFJ}$ and those jointed by LFJ are not clear in the case of in-plane bending. The ratio $f_{m_{-} \text {in }} 05 \% / F_{b_{-} i n}$ showed 1.26 to 1.77 except for the case of the 3L3P_NF_W-W group whose CV showed the maximum value of $18.6 \%$ among all specimen groups. These results indicate that the finger-jointed CLT panels met the requirement for the characteristic in-plane bending strength assigned to the non-finger jointed CLT panels (MLIT 2018) except for one case. It might be recommended that the 3L3P CLT panel should not be jointed in the weak direction using the normal finger joint.

From Table 3, in the case of in-plane bending, the differences in the MoE between the specimens jointed by LFJ and those jointed by NFJ were not clear. The ratios $E_{m_{-} i_{-} 50 \%} / E_{\mathrm{b}_{-} \text {in }}$ showed 1.29 to 1.62 in the S-S groups, and 2.24 to 2.78 in the W-W groups, respectively. These results seem to be affected by the two factors mentioned in the case of the out-of-plane bending. The effects of the two factors, however, are smaller in the case of in-plane bending than in the case of the out-of-plane bending.

The apparent strength ratios of the corresponding CLT specimens showed reasonable values of 0.78 to 0.98 regardless of the joint direction. While in the case of the apparent stiffness ratios, the evaluation results showed that the effect of finger joints on the elastic stiffness of finger joint CLT panels is smaller than the effect on strength.

\subsection{In-Plane Shear}

Figure 7 shows the shear stress $(\tau)$ - shear strain $(\gamma)$ relationships and typical failure phenomena observed from the in-plane shear test.

\section{Fig. $7 \tau-\gamma$ relationships and typical failure phenomena of finger jointed CLT specimens \\ subjected to in-plane shear force.}

Table 4 shows the results of the in-plane shear test. In Table $4, F_{S_{i} \text { in }}$ indicates the characteristic in-plane shear strength of the CLT panel estimated by equation (14) that was given in the Notification \#1324 (MLIT 2018) and $G_{S_{-} i n}$ indicates the design shear rigidity given by equation (15) (Japan HOWTEC \& Japan CLT Association 2016). On the other hand, $f_{S_{-} i n \_a v g}, f_{S_{-} i n \_05 \%}$ indicate the average strength value and the lower $5 \%$ strength value, and $G_{S_{-} i n_{-} a v g}, G_{S_{-} i n \_50 \%}$ indicate the average stiffness value and the lower $50 \%$ stiffness value, all are evaluated from six experimental data in each specimen group.

Table 4 Results of In-Plane Shear Test

As the ratio of $S / d$ and ald of the $\mathrm{W}-\mathrm{W}$ specimen group was 1.5 as shown in Table1, diagonal force transmissions between the upper loading block and the lower supporting block were confirmed subject to the assumption that force will expand to 45 degrees through transversal layers. Therefore, a kind of reduction factor, how much percentage of applied load contributed to the shear behavior, was multiplied by the observed applied load to evaluate a correct shear strength and a correct shear rigidity of the W-W specimen group. The values of reduction factors were $76.3 \%$ for the 3L3P_W-W group, 71.6\% for the 5L5P_W-W group, and 79.7\% for the 5L7P_W-W group. The details, how the reduction factors were derived, are shown in the Online Resource-4.

From Fig. 7 and Table 4, the differences in the performance between the specimens jointed by NFJ and those jointed by LFJ are not clear. The ratio $f_{s_{-} \text {in } \_5 \%} / F_{s_{-} \text {in }}$ showed 1.1 to 2.2 except for the case of 3L3P_NF_W-W group whose CV showed $23.8 \%$. The ratio $G_{S_{-} \text {in_50\% }} / G_{S_{-} \text {in }}$ showed 1.03 to 1.56 except for the case of 3L3P_NF_W-W group whose CV showed 36.0\%. These results indicate that the in-plane shear performance of finger-jointed CLT panel almost, except for one case, met the requirement for the non-bonded CLT panel assigned by the Notification \#1342 as well as proposed by the commercial sectors. Therefore, it might be recommended that the 3L3P CLT panel should not be jointed in the weak direction using the normal finger joint.

As there are many difficulties to obtain a pure in-plane shear strength of full-scale CLT panel, various ideas on the testing methods for evaluating the in-plane shear performance of CLT panels have been proposed (Bosl 2002; Bogensperger et al. 2007; Jöbstl et al. 2008; Andreolli et al. 2012; Gagnon et al. 2014; Brander et al. 2015; 
Main Text revised

Nakashima et al. 2019). In any case, each test method has advantages and disadvantages, and the weak axis performance unique to CLT is complicated, so that the method successful in lumber or glulam may not work well in CLT. Further studies are needed to establish a rational evaluation method for the full-scale in-plane shear strength of CLT.

\subsection{Out-of-Plane Shear}

Figure 8 shows load $(P)$ - deflection $(\delta)$ relationships and typical failure phenomena observed from the out-of-plane shear test.

Fig.8 $P-\delta$ relationships and typical failure phenomena of finger jointed CLT specimens
subjected to out-of-plane shear force.

Table 5 shows the results of the out-of-plane shear test. In Table $5, F_{S_{-} o u t}$ indicates the characteristic out-of-plane shear strength of the CLT panel estimated by equation (16) that was given in the Notification \#1324 (MLIT 2018). On the other hand, $f_{S_{-} \text {out_avg }}, f_{S_{-} \text {out_05\% }}$ indicate the average value and lower 5\% strength value evaluated from six experimental data in each specimen group.

\section{Table 5 Results of Out-of-Plane Shear}

In the three-point loading shear test recommended by ISO 13910 (2014) and JAS standard (MAFF 2013), the failure mode was affected by the balance between maximum bending stress and maximum shear stress depending on the geometrical and mechanical factors of the specimen. As the consequence, it was quite difficult to obtain pure shear failure by this test method. Most failure initiated from "bending failure" at finger joint, afterward rolling shear failure was observed in some cases. In the case of a 3L3P specimen, the percentage of bending failure was $100 \%$. In the case of 5L5P specimen, only 5L5P_LF_S-S showed rolling shear failure (in total, bending failure mode was 95.8\%), and in the case of 5L7P specimen, two 5L7P_NF_S-S and one 5L7P_NF_W-W showed rolling shear failure (in total, bending failure mode was $75 \%$ ). It may be said from these results that the testing method for evaluating out-of-plane shear strength should be changed to a more appropriate method in which pure shear failure can always be obtained.

In ISO 13910 (2014), it is described that "some specimens may fail in modes other than shear, e.g. in bending or compression perpendicular to the grain. However, all test results shall be used to evaluate shear strength properties". It is supposed that the JAS standard (MAFF 2013) is accepting the spirit of the ISO standard (ISO 139102014 ). Hence, if we obey the suggestion of the ISO by ignoring failure modes, from the ratios $f_{S_{-} \text {out_05\% }} / F_{S_{-} \text {out }}$ shown in Table 5, it may be said that the NF joint should not be used for expanding CLT panels in weak-weak direction, and for expanding CLT panels in strong-strong direction, both NF and LF joints might be possible to use.

\subsection{Compression}

Figure 9 shows the load $(P)$ - deformation $(v)$ relationships and typical failure phenomena observed from the compression test.

\section{Fig.9 $P-v$ relationships and typical failure phenomena of finger jointed CLT specimens} subjected to compression force.

Table 6 shows the results of the compression test. In Table $6, F_{C}$ indicates the characteristic compressive strength of CLT panel estimated by equation (19) that was given in the Notification \#1324 (MLIT 2018) and $E_{C}$ indicates the design modulus of elasticity estimated by equation (22) (Japan HOWTEC \& Japan CLT Association 2016). On the other hand, $f_{C_{-} a v g}, f_{C_{-} 05 \%}$ indicate the average strength value and the lower $5 \%$ strength value, and $E_{C_{-} a v g}$, $E_{C_{-} 50 \%}$ indicate the average stiffness value and the lower $50 \%$ stiffness value, all are evaluated from six experimental data in each specimen group. The specimen groups marked with "*2" represent non-finger-jointed CLT 
Main Text revised

panels (controls).

\section{Table 6 Results of Axial Compression Test}

From Table 6, the ratio $f_{\mathrm{c}_{-} 05 \%} / F_{\mathrm{c}}$ showed 1.38 to 2.06 for the S-S group and 2.26 to 4.88 for the W-W group, respectively. These results indicate that the finger-jointed CLT panels met the requirement for the characteristic axial compressive strength assigned to the non-finger jointed CLT panels (MLIT 2018). The slightly lower values in the S-S group were supposed to be caused mainly by a conservative assumption that transversal Young's modulus was assumed to be zero. While higher values in 3L3P_W-W groups were caused by the severe assumption that contributions from outer plies had to be ignored so that the effective slenderness ratio $\lambda$ became larger than the reality.

The ratio $E_{\mathrm{c}-50 \%} / E_{\mathrm{c} \text {-CLT }}$ showed 1.17 to 1.81 for the S-S group and 2.14 to 2.53 for the W-W group, respectively. These results seem to be reasonable. In the cases of modulus of elasticity, nearly the same reasons as described in the case of strength will be held, although their effect on the stiffness was relatively smaller compared with the case of strength.

Among all destructive tests executed in this research, only axially loaded CLT panels showed nonlinear behaviors in the load-deformation curves as can be seen from Fig. 9. These phenomena are mainly caused by sophisticated buckling deformations of CLT panel initiated by peeling along the glue-lines of each ply or penetration of finger-tip(s) into finger-valley(s).

The strength and stiffness ratios of the axial compression specimens showed reasonable values of 0.74 to 0.80 , and 0.88 to 0.96 , respectively. Among the three different control tests, this compression test was the only real control one because the test specimens belonged to the same product as that of the specimens used in these research experiments. Hence, joint efficiencies obtained from the compression test will be the most reliable values.

\section{Conclusion}

In this study, mechanical performances of finger-jointed CLT panels were evaluated based on the Japanese domestic testing standard according to the evaluation policy described in section 1.2.2. The findings obtained are summarized as follows:

- The appropriate push-in pressure value commonly used for producing finger-jointed CLT specimens was decided to be $1 \mathrm{~N} / \mathrm{mm}^{2}$, considering the possibility of the on-site finger jointing condition.

- Except for the following two cases, most finger-jointed CLT specimens met the strength requirements for the non-finger jointed CLT products assigned by MLIT of Japan.

- The lower 5\% strength value of the 3L3P_NF_W-W group subjected to the in-plane bending load could not satisfy the assigned characteristic strength value.

- The lower 5\% strength value of all W-W groups subjected to the out-of-plane shear load could not satisfy the assigned characteristic strength value. These issues are supposed to be caused partly by the inappropriate testing method in which $100 \%$ of the 3L3P group, $95.8 \%$ of the 5L5P group, and $75 \%$ of the 5L7P group failed by "bending".

- The apparent strength ratio of finger jointed CLT panels subjected to the out-of-plane and in-plane bending showed a reasonable range of values in the case of strong-strong groups. While in the case of the weak-weak group, it was variable due to the inherent inferior performance of transversal layers involved in the CLT panel.

- Axially loaded CLT panels only showed nonlinear behavior in the load-deformation curves, while the rest of all specimens showed almost linear load-deflection curve up to the maximum load and just after they failed in brittle fracture mode.

- The strength and stiffness ratios of finger-jointed CLT panels subjected to the axial compression load showed reasonable values of 0.74 to 0.80 , and 0.88 to 0.96 , respectively. 
- All specimens satisfied the proposed design stiffness values. These results do not always imply the excellent stiffness of finger-jointed CLT panels, but they may be partly caused by the excessively safe-side assumption that Young's modulus of the transversal laminae in CLT had to be assumed to be zero in the design equations.

\section{Acknowledgments}

The authors appreciate the financial support given by the Japanese Forestry Agency (the 2017 Forestry Agency Commissioned Business), and all members who collaborated to drive this large-scale research project smoothly.

\section{Declaration of Conflicting Interests}

The authors declared no potential conflicts of interest with respect to the research, authorship, and/or publication of this article.

\section{References}

Aicher S, Bornschlegl V, Herr J (1997) Numerical and Full-Scale Experimental Investigations on Glulam Frame Corners with Large Finger Joints, International Conference of IUFRO S5.02, Timber Engineering, Copenhagen, pp.239-258.

AIJ Standard (2006) Architectural Institute of Japan (edited), Standard for Structural Design of Timber Structures, Fourth edition; $1^{\text {st }}$ print, Maruzen. (in Japanese)

Andreolli M, Tomasi R, Polastri A (2012) Experimental investigation on in-plane behaviour of cross-laminated timber elements, In: Proc. of the CIB-W18 Meeting 45, Paper No. CIB-W18/45-12-4, August, VÄXJÖ, Sweden.

Anshari B, Guan ZW, Kitamori A, Jung K, Hassel I, Komatsu K (2011) Mechanical and moisture-dependent swelling properties of compressed Japanese cedar, Construction and Building Materials, 25, 1718-1725

ANON (2016) Test report issued by the Kagoshima Prefectural Institute of Industrial Technology, Confidential Matter, (in Japanese)

ASTM D1990-00 (2002) Standard Practice for Establishing Allowable Properties for Visually-Graded Dimension Lumber from In-Grade Tests of Full-Size Specimens, West Conshohocken, PA 19428-2959, USA.

ASTM D2915-03 (2003) Standard Practice for Evaluating Allowable Properties for Grades of Structural Lumber, West Conshohocken, PA 19428-2959, USA.

ASTM D198-05a (2005a) Standard Test Methods of Static Tests of Lumber in Structural Sizes, West Conshohocken, PA 19428-2959, USA.

ASTM D4761-05 (2005b) Standard Test Methods for Mechanical Properties of Lumber and Wood-Base Structural Material, West Conshohocken, PA 19428-2959, USA.

Bernasconi A (2012) Timber Construction in the City of Milan - 4 Residential Buildings with 9 Storey https://www.yumpu.com/en/document/view/6217094/residential-building-via-cenni-traeblogdk

(Accessed on 14 August 2020)

Blaß HJ, Flaig M (2015) Keilgezinkte Rahmenecken und Satteldachträger aus Brettsperrholz (Finger-jointed frame corners and gable roof beams made of cross laminated timber), Karlsruher Berichte zum Ingenieurholzbau, Band 29, Karlsruher Institut für Technologie (KIT) Holzbau und Baukonstruktionen, 196pages, DOI $10.5445 / \mathrm{KSP} / 1000047039$

Bogensperger T, Moosbrugger T, Schickhofer G (2007) New Test Configuration For CLT-Wall-Elements Under Shear Load, In: Proc. of the CIB-W18 Meeting 40, Paper No. CIB-W18/40-21-2, August, Bled, Slovenia.

Bosl R (2002) Zum Nachweis des Trag- und Verformungsverhaltens von Wandscheiben aus Brettlagenholz (To 
Main Text revised

prove the load-bearing and deformation behavior of wall panels made of glued composite timbers), Dissertation, Universität der Bundeswehr München, Fakultät für Bauingenieur- und Vermessungswesen Konstruktive Gestaltung und Holzbau. https://d-nb.info/96509846x/34 (Accessed on 30 July 2020)

Brandner R, Gatternig W, Schickhofer G (2012) Determination of Shear Strength of Structural and Glued Laminated Timber, In: Proc. of the CIB-W18 Meeting 45, Paper No. CIB-W18/45-12-2, August, Växjö, Sweden.

Brandner R (2013) Production and Technology of Cross Laminated Timber (CLT): A state-of-the-art Report. In Focus Solid Timber Solutions - European Conference on Cross Laminated Timber (CLT) (pp. 3-36). Bath: University of Bath.

https://graz.pure.elsevier.com/en/publications/production-and-technology-of-cross-laminated-timber-clt-a-stateo (Accessed on 14 July 2020)

Brandner R, Dietsch P, Dröscher J, Schulte-Wrede M, Kreuzinger H, Sieder M, Schickhofer G, Winter S (2015) Shear Properties of Cross Laminated Timber (CLT) under in - plane load: Test Configuration and Experimental Study, In: Proc. INTER Meeting 48, Paper Number INTER / 48-12-02, Šibenik, Croatia

Brandner R, Flatscher G, Ringhofer A, Schickhofer G, Thiel A (2016) Cross laminated timber (CLT): overview and development, Eur. J. Wood Prod., DOI 10.1007/s00107-015-0999-5

EN 408 (1995) Standard timber structures. Structural timber and glued laminated timber. Determination of some physical and mechanical properties, European Committee for Standardization, CEN, Brussels, Belgium

EN 308 (2004) Standard structural timber. Determination of characteristic values of mechanical properties and density, European Committee for Standardization, CEN, Brussels, Belgium

EN14358 (2006) Timber structures - Calculation of characteristic 5-percentile values and acceptance criteria for a sample, European Committee for Standardization, CEN, Brussels, Belgium

EN16351 (2015) Timber structures - Cross laminated timber - Requirements. European Committee for Standardization, CEN, Brussels, Belgium

FFPRI (2015) Forestry and Forest Products Research Institute, Hokkaido Forest Products Research Institute, Japan CLT Association. Report on the Promotion of Practical Use of CLT (Collection and Analysis of Strength Data), 2013 Forestry Agency Outsourced Business by Supplementary Budget, 122pages. (in Japanese) http://www.ffpri.affrc.go.jp/pubs/various/documents/h25cltkyoudo.pdf (Accessed on 28 July 2020)

Flaig M, Blaß H J (2013) Shear strength and shear stiffness of CLT-beams loaded in plane, In: Proc. of the CIB-W18 Meeting 46, Paper No. CIB-W18/46-12-3, 26-29 August, Vancouver, Canada.

Gagnon S, Mohammad M, Toro WM, Popovski W (2014) Evaluation of In-Plane Shear Strength of CLT, In: Proc. World Conference on Timber Engineering 2014, August, Quebec, Canada.

Horie H, Kurata H (1984) Strength Properties of Structural Finger-Jointed Lumber (I), Report of the Hokkaido Forest Product Research Institute, No.73, pp.1-34. (in Japanese)

https://agriknowledge.affrc.go.jp/RN/2010292897.pdf (Accessed on 10 June 2019)

ISO 13910 (2005) Structural timber - Sampling, full-size testing, and evaluation of the characteristic values of strength graded timber, Geneva, Switzerland (at present, this old version was withdrawn)

ISO 13910 (2014) Timber structures - Strength-graded timber - Test method for structural properties, Geneva, Switzerland

Japan CLT Association (2020) Home page of Japan Cross laminated Timber Association, (in Japanese) http://clta.jp/ (Accessed on 28 July 2020)

Japan HOWTEC (1992) Project Report on Constituting Standard Design Manual for Promoting Wooden Constructions, (3) Development of Glued Laminated Timber Joint by On-Site Gluing, 547pages, organized by Japan Housing and Wood Technology Center (HOWTEC) (in Japanese), http://www.kiwoikasu-plat.jp/contents/book/docs/590/1991-020.pdf （Accessed on 10 June 2019) 
Japan HOWTEC (2011) Strength Test Manual for Structural Timber, Organized by Japan Housing and Wood Technology Center (HOWTEC) (in Japanese)

Japan HOWTEC \& Japan CLT Association (2016) Section 14 "Materials and Durability", pp.177-211, in Design and Construction Manual for the Buildings using CLT (2016), edited by Japan Housing and Wood Technology Center (HOWTEC), Organized by Japan HOWTEC and Japan CLT Association under Supervisions of National Institute for Land and Infrastructure Management (NILIM) and Building Research Institute (BRI), (in Japanese)

Jöbstl RA, Bogenperger Th, Schickhofer G (2008) In-Plane Shear Strength of Cross Laminated Timber, In: Proc. of the CIB-W18 Meeting 41, Paper No. CIB-W18/41-12-3, August, St. Andrews, Canada.

Komatsu K, Nitta A, Kawahara S, Kitamori A, Noda Y, Aicher S (2001) Moment-Resisting Performance of Glulam Beam-to-Column Joints Composed of Various Types of Large Finger Joints, Proceedings of the Symposium on Joints in Timber Structures, 55 $5^{\text {th }}$ RILEM Annual Week, Stuttgart, Germany, $12^{\text {th }}$ to $14^{\text {th }}$ September.

MAFF (2013), Japanese Agricultural Standard (JAS) No.3079 for Cross Laminated Timber issued on $20^{\text {th }}$ December 2013. Ministry of Agriculture, Forestry and Fishery (in Japanese),

http://www.maff.go.jp/j/jas/jas_kikaku/pdf/kikaku_clt.pdf (Accessed on 24 August 2019)

MLIT (2018) On The Revision of Some Parts of Specific Allowable Stress and Strength of Materials, Notification \#1324 issued on $12^{\text {th }}$ December 2018. Ministry of Land, Infrastructure and Tourism (in Japanese) http://www.mlit.go.jp/common/001264970.pdf (Accessed on 24 August 2019)

Nakashima S, Araki Y, Ohashi Y, Nakajima S, Miyatake A (2019) Evaluation of In-Plane Shear Strength of CLT Based on The Real Size Horizontal Loading Shear Test - The effect of species of laminae on in-plane shear strength, J. Struct. Constr. Eng., AIJ, 84 (760): 843-849 (in Japanese)

https://www.jstage.jst.go.jp/article/aijs/84/760/84_843/_article/-char/en (Accessed on 30 July 2020)

Noda Y, Mori T, Komatsu K (2013) Estimation of Joint Strength of Large-Finger-Jointed Glued Laminated Timber, Journal of Material Science, Japan, 62(4):274-279. (in Japanese) https://www.jstage.jst.go.jp/article/jsms/62/4/62_274/_article/-char/en (Accessed on $9^{\text {th }}$ June 2019)

Schickhofer G (2013) CLT - European Experience -Idea \& Development Technology \& Applications -, Handout Reference Distributed in CLT Forum 2013 in TOKYO, $24^{\text {th }}$ October. http://clta.jp/wp-content/uploads/2013/10/20131024_SCHICKHOFER_I_part-1_Tokyo-01.pdf (Accessed on 13 August 2020)

Yates M, Linegar M (2008) "Murray Grove - A Case Study in the Use of Cross Laminated Solid Timber Panels for the Construction of Medium Rise Buildings", In; Proceedings of World Conference of Timber Engineering (WCTE 2008), Miyazaki, 2008.

Zeng XY, Ren SX, Omar S (2009) Vertical Displacements in a Medium-Rise Timber Building - Limnologen in Växjö, Sweden, Diploma thesis, Department of Technology and Design, Växjö University. http://www.diva-portal.org/smash/get/diva2:226491/FULLTEXT01.pdf (Accessed on 14 August 2020) 
Table 1 Specification of the test specimens

\begin{tabular}{|c|c|c|c|c|c|c|}
\hline \multirow{3}{*}{ Kinds of Test } & $d$ & $b$ & $e$ & $a$ & $S$ & $L$ \\
\hline & Depth & Width & Extra length & Shear span & $\begin{array}{c}\text { Length of } \\
\text { constant } \\
\text { moment or } \\
\text { shear }\end{array}$ & Total span \\
\hline & \multicolumn{6}{|c|}{$(\mathrm{mm})$} \\
\hline Out-of-Plane Bending & $30 \times$ Plies & 300 & $d$ & $6 d$ & $6 d$ & $S+2 a$ \\
\hline In-Plane Bending & 240 & $30 \times$ Plies & 200 & 1200 & 1200 & $S+2 a$ \\
\hline Out-of-Plane Shear & $30 \times$ Plies & 240 & $d$ & $3 d$ & - & $2 a$ \\
\hline In-plane Shear & 240 & $30 \times$ Plies & $\begin{array}{c}\mathrm{S}-\mathrm{S}: 2.5 d \\
\mathrm{~W}-\mathrm{W}: 3.25 d\end{array}$ & $\begin{array}{c}\mathrm{S}-\mathrm{S}: 2 d \\
\mathrm{~W}-\mathrm{W}: 1.5 d\end{array}$ & $a$ & $S+2 a$ \\
\hline Axial Compression & 200 & $30 \times$ Plies & - & - & - & 890 \\
\hline
\end{tabular}


Table 2 Results of out-of-plane bending test

\begin{tabular}{|c|c|c|c|c|c|c|c|c|c|c|c|}
\hline \multirow{4}{*}{\multicolumn{2}{|c|}{$\begin{array}{c}\text { Specimen } \\
\text { Group name }\end{array}$}} & \multicolumn{5}{|c|}{ Modulus of rupture (MoR) } & \multicolumn{5}{|c|}{ Modulus of elasticity (MoE) } \\
\hline & & \multirow{2}{*}{$\frac{\# 1324}{F_{b_{-} \text {out }}}$} & \multicolumn{3}{|c|}{ Experiment } & \multirow{3}{*}{$\frac{f_{m_{\_} \text {out_05\% }}}{F_{b_{-} \text {out }}}$} & Design & \multicolumn{2}{|c|}{ Experiment } & \multirow{3}{*}{$\frac{\mathrm{CV}}{\%}$} & \multirow{3}{*}{$\frac{E_{m_{\_} \text {out_50\% }}}{E_{b_{-} \text {out }}}$} \\
\hline & & & $f_{m \_o u t \_a v g}$ & $f_{m \_o u t \_05 \%}$ & $\mathrm{CV}$ & & $E_{b_{-} \text {out }}$ & $E_{m \_o u t \_a v g}$ & $E_{m \_o u t \_50 \%}$ & & \\
\hline & & \multicolumn{3}{|c|}{$\mathrm{N} / \mathrm{mm}^{2}$} & $\%$ & & \multicolumn{3}{|c|}{$\mathrm{kN} / \mathrm{mm}^{2}$} & & \\
\hline \multirow{7}{*}{ 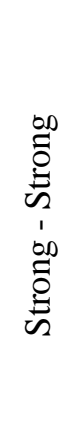 } & 3L3P_LF_S-S & 12.68 & 25.23 & 18.63 & 11.2 & 1.47 & 5.78 & 5.97 & 5.93 & 2.3 & 1.03 \\
\hline & 3L3P_NF_S-S & 12.68 & 23.30 & 13.33 & 18.3 & 1.05 & 5.78 & 6.13 & 6.02 & 5.8 & 1.04 \\
\hline & 5L5P_LF_S-S & 10.37 & 21.89 & 17.26 & 9.1 & 1.66 & 4.73 & 6.07 & 6.02 & 2.5 & 1.27 \\
\hline & 5L5P_NF_S-S & 10.37 & 17.63 & 11.26 & 15.5 & 1.09 & 4.73 & 5.52 & 5.44 & 4.9 & 1.15 \\
\hline & 5L5P_S_ct $* 1$ & 10.37 & 26.60 & 19.78 & 11.0 & 1.91 & 4.73 & 6.14 & 6.03 & 5.9 & 1.28 \\
\hline & 5L7P_NF_S-S & 12.15 & 20.27 & 13.69 & 13.9 & 1.13 & 5.54 & 5.91 & 5.89 & 1.2 & 1.06 \\
\hline & 5L7P_S_ct $* 1$ & 12.15 & 26.45 & 21.50 & 8.0 & 1.77 & 5.54 & 6.89 & 6.84 & 2.3 & 1.24 \\
\hline \multirow{7}{*}{ 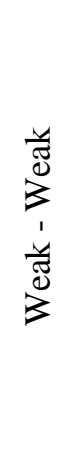 } & 3L3P_LF_W-W & 0.35 & 4.87 & 3.49 & 12.1 & 9.93 & 0.11 & 0.50 & 0.49 & 7.7 & 4.44 \\
\hline & 3L3P_NF_W-W & 0.35 & 5.04 & 3.42 & 13.8 & 9.72 & 0.11 & 0.59 & 0.55 & 21.2 & 4.99 \\
\hline & 5L5P_LF_W-W & 1.98 & 12.16 & 7.97 & 14.7 & 4.03 & 0.62 & 1.81 & 1.76 & 9.2 & 2.82 \\
\hline & 5L5P_NF_W-W & 1.98 & 9.70 & 7.05 & 11.7 & 3.56 & 0.62 & 1.75 & 1.70 & 8.8 & 2.73 \\
\hline & 5L5P_W_ctl ${ }^{* 1}$ & 1.98 & 11.11 & 7.63 & 13.4 & 3.86 & 0.62 & 1.47 & 1.45 & 4.1 & 2.33 \\
\hline & 5L7P_NF_W-W & 0.72 & 6.63 & 3.81 & 18.2 & 5.28 & 0.23 & 0.86 & 0.85 & 3.7 & 3.75 \\
\hline & 5L7P_W_ctl*1 & 0.72 & 5.57 & 3.82 & 13.5 & 5.30 & 0.23 & 0.75 & 0.74 & 4.0 & 3.26 \\
\hline \multirow{6}{*}{\multicolumn{2}{|c|}{ Apparent strength ratio }} & \multicolumn{3}{|c|}{$(5 \mathrm{~L} 5 \mathrm{P}$ _LF_S-S) $/(5 \mathrm{~L} 5 \mathrm{P}$ _S_ctl) $=$} & 0.82 & \multirow{6}{*}{\multicolumn{2}{|c|}{$\begin{array}{c}\text { Apparent stiffness } \\
\text { ratio }\end{array}$}} & \multicolumn{3}{|c|}{$(5 \mathrm{~L} 5 \mathrm{P}$ LLF_S-S)/(5L5P_S_ctl) $=$} & 0.99 \\
\hline & & \multicolumn{3}{|c|}{$(5 \mathrm{~L} 5 \mathrm{P}$ NF_S-S $) /(5 \mathrm{~L} 5 \mathrm{P}$ _S_ctl) $=$} & 0.66 & & & \multicolumn{3}{|c|}{$(5 \mathrm{~L} 5 \mathrm{P}$ NFF_S-S $) /(5 \mathrm{~L} 5 \mathrm{P}$ _S_ctl) $=$} & 0.90 \\
\hline & & \multicolumn{3}{|c|}{$(5 \mathrm{~L} 7 \mathrm{P}$ NFF_S-S $) /(5 \mathrm{~L} 7 \mathrm{P}$ _S_ctl) $=$} & 0.77 & & & \multicolumn{3}{|c|}{$(5 \mathrm{~L} 7 \mathrm{P}$-NF_S-S $) /(5 \mathrm{~L} 7 \mathrm{P}$ _S_ctl $)=$} & 0.86 \\
\hline & & \multicolumn{3}{|c|}{$(5 \mathrm{~L} 5 \mathrm{P}$ _LF_W-W $) /(5 \mathrm{~L} 5 \mathrm{P}$ _W_ctl) $=$} & 1.01 & & & \multicolumn{3}{|c|}{$(5 \mathrm{~L} 5 \mathrm{P}$ _LF_W-W)/(5L5P_W_ctl) $=$} & 1.23 \\
\hline & & \multicolumn{3}{|c|}{$(5 \mathrm{~L} 5 \mathrm{P}$ _NF_W-W $) /(5 \mathrm{~L} 5 \mathrm{P}$-W_ctl $)=$} & 0.87 & & & \multicolumn{3}{|c|}{$(5 \mathrm{~L} 5 \mathrm{P}$ _NF_W-W)/(5L5P_W_ctl) $=$} & 1.19 \\
\hline & & \multicolumn{3}{|c|}{$\left(5 \mathrm{~L} 7 \mathrm{P} \_N F\right.$ NW-W $) /(5 \mathrm{~L} 7 \mathrm{P}$ _W_ctl $)=$} & 1.19 & & & \multicolumn{3}{|c|}{$\left(5 \mathrm{~L} 7 \mathrm{P} \_N F \_W-W\right) /\left(5 \mathrm{~L} 7 \mathrm{P} \_\mathrm{W} \_c t l\right)=$} & 1.15 \\
\hline
\end{tabular}

*1: Control CLT panel specimens without finger joints (ANON 2016) 
Table 3 Results of in-plane bending test

\begin{tabular}{|c|c|c|c|c|c|c|c|c|c|c|c|}
\hline & \multirow{4}{*}{$\begin{array}{c}\text { Specimen } \\
\text { Group Name }\end{array}$} & \multicolumn{5}{|c|}{ Modulus of rupture (MoR) } & \multicolumn{5}{|c|}{ Modulus of elasticity (MoE) } \\
\hline & & \multirow{2}{*}{$\begin{array}{l}\# 1324 \\
F_{b_{-} \text {in }} \\
\end{array}$} & \multicolumn{3}{|c|}{ Experiment } & \multirow{3}{*}{$\frac{f_{m_{-} i n_{-} 05 \%}}{F_{b_{-} i n}}$} & Design & \multicolumn{3}{|c|}{ Experiment } & \multirow{3}{*}{$\frac{E_{m \_i n \_50 \%}}{E_{b_{-} i n}}$} \\
\hline & & & $f_{m \_i n \_a v g}$ & $f_{m \_o u t \_05 \%}$ & $\mathrm{CV}$ & & $E_{b_{-} \text {in }}$ & $E_{m \_i n \_a v g}$ & $E_{m \_i n \_50 \%}$ & $\mathrm{CV}$ & \\
\hline & & \multicolumn{3}{|c|}{$\mathrm{N} / \mathrm{mm}^{2}$} & $\%$ & & \multicolumn{3}{|c|}{$\mathrm{kN} / \mathrm{mm}^{2}$} & $\%$ & \\
\hline \multirow{7}{*}{ 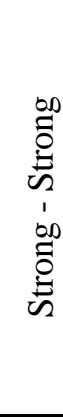 } & 3L3P_LF_S-S & 10.80 & 18.38 & 13.62 & 11.1 & 1.26 & 4.00 & 5.55 & 5.39 & 10.0 & 1.35 \\
\hline & 3L3P_NF_S-S & 10.80 & 21.32 & 14.95 & 12.8 & 1.38 & 4.00 & 5.65 & 5.58 & 4.6 & 1.39 \\
\hline & 5L5P_LF_S-S & 8.10 & 17.64 & 14.34 & 8.0 & 1.77 & 3.00 & 4.77 & 4.73 & 2.5 & 1.58 \\
\hline & 5L5P_NF_S-S & 8.10 & 16.75 & 12.46 & 11.0 & 1.54 & 3.00 & 4.90 & 4.85 & 3.3 & 1.62 \\
\hline & 5L5P_S_ctl*1 & 8.10 & 18.50 & 12.71 & 13.4 & 1.57 & 3.00 & 4.67 & 4.60 & 4.8 & 1.53 \\
\hline & 5L7P_NF_S-S & 10.41 & 17.46 & 13.69 & 9.2 & 1.31 & 3.86 & 5.02 & 4.97 & 3.5 & 1.29 \\
\hline & 5L7P_S_ctl*1 & 10.41 & 22.48 & 18.33 & 7.9 & 1.76 & 3.86 & 5.34 & 5.27 & 4.5 & 1.37 \\
\hline \multirow{7}{*}{ 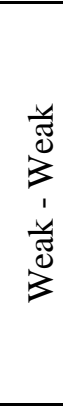 } & 3L3P_LF_W-W & 5.40 & 10.82 & 8.16 & 10.5 & 1.51 & 1.00 & 2.72 & 2.61 & 13.2 & 2.61 \\
\hline & 3L3P_NF_W-W & 5.40 & 8.26 & 4.67 & 18.6 & 0.87 & 1.00 & 2.35 & 2.24 & 15.7 & 2.24 \\
\hline & 5L5P_LF_W-W & 6.48 & 13.65 & 11.36 & 7.2 & 1.75 & 1.20 & 3.20 & 3.14 & 6.4 & 2.62 \\
\hline & 5L5P_NF_W-W & 6.48 & 13.43 & 10.15 & 10.4 & 1.57 & 1.20 & 3.30 & 3.23 & 7.5 & 2.69 \\
\hline & 5L5P_W_ctl*1 & 6.48 & 13.92 & 10.24 & 11.3 & 1.58 & 1.20 & 2.72 & 2.69 & 3.5 & 2.24 \\
\hline & 5L7P_NF_W-W & 4.63 & 8.36 & 7.12 & 6.3 & 1.54 & 0.86 & 2.42 & 2.38 & 5.5 & 2.78 \\
\hline & 5L7P_W_ctl*1 & 4.63 & 9.95 & 7.26 & 11.6 & 1.57 & 0.86 & 1.93 & 1.90 & 5.8 & 2.22 \\
\hline \multirow{6}{*}{\multicolumn{2}{|c|}{ Apparent strength ratio }} & \multicolumn{3}{|c|}{ (5L5P_LF_S-S)/(5L5P_S_ctl) $=$} & 0.95 & \multirow{6}{*}{\multicolumn{2}{|c|}{$\begin{array}{l}\text { Apparent stiffness } \\
\text { ratio }\end{array}$}} & \multicolumn{3}{|c|}{$($ 5L5P_LF_S-S)/(5L5P_S_ctl) $=$} & 1.02 \\
\hline & & \multicolumn{3}{|c|}{$\left(5 \mathrm{~L} 5 \mathrm{P} \_\mathrm{NF} \_\mathrm{S}-\mathrm{S}\right) /\left(5 \mathrm{~L} 5 \mathrm{P} \_\mathrm{S}\right.$ _ctl $)=$} & 0.91 & & & \multicolumn{3}{|c|}{$\left(5 \mathrm{~L} 5 \mathrm{P} \_N F\right.$ _S-S $) /\left(5 \mathrm{~L} 5 \mathrm{P} \_\mathrm{S} \_\mathrm{ctl}\right)=$} & 1.05 \\
\hline & & \multicolumn{3}{|c|}{$($ 5L7P_NF_S-S $) /\left(5 \mathrm{~L} 7 \mathrm{P} \_S\right.$ Sctl $)=$} & 0.78 & & & \multicolumn{3}{|c|}{ (5L7P_NF_S-S)/(5L7P_S_ctl) $=$} & 0.94 \\
\hline & & \multicolumn{3}{|c|}{$(5 \mathrm{~L} 5 \mathrm{P}+\mathrm{LF}$ _W-W $) /\left(5 \mathrm{~L} 5 \mathrm{P} \_\mathrm{W} \_\mathrm{ctl}\right)=$} & 0.98 & & & \multicolumn{3}{|c|}{$($ 5L5P_LF_W-W)/(5L5P_W_ctl) $=$} & 1.18 \\
\hline & & \multicolumn{3}{|c|}{$(5 \mathrm{~L} 5 \mathrm{P}$-NF_W-W $) /\left(5 \mathrm{~L} 5 \mathrm{P} \_\mathrm{W}\right.$ _ctl $)=$} & 0.97 & & & \multicolumn{3}{|c|}{$(5 \mathrm{~L} 5 \mathrm{P}$ _NF_W-W $) /(5 \mathrm{~L} 5 \mathrm{P}$ _W_ctl) $=$} & 1.21 \\
\hline & & \multicolumn{3}{|c|}{$\left(5 \mathrm{~L} 7 \mathrm{P} \_N F \_W-W\right) /\left(5 \mathrm{~L} 7 \mathrm{P} \_\mathrm{W} \_c t l\right)=$} & 0.84 & & & \multicolumn{3}{|c|}{$($ 5L7P_NF_W-W $) /(5 \mathrm{~L} 7 \mathrm{P}$ _W_ctl) $=$} & 1.25 \\
\hline
\end{tabular}

*1: Control CLT panel specimens without finger joints (ANON 2016) 
Table 4 Results of in-plane shear

\begin{tabular}{|c|c|c|c|c|c|c|c|c|c|c|c|}
\hline \multirow{4}{*}{\multicolumn{2}{|c|}{$\begin{array}{c}\text { Specimen Group } \\
\text { Name }\end{array}$}} & \multicolumn{5}{|c|}{ In-plane shear strength } & \multicolumn{5}{|c|}{ In-plane shear rigidity } \\
\hline & & \multirow{2}{*}{$\begin{array}{l}\# 1324 \\
F_{S_{-} \text {in }} \\
\end{array}$} & \multicolumn{3}{|c|}{ Experiment } & \multirow{3}{*}{$\frac{f_{S_{-} i n_{-} 05 \%}}{F_{S_{-} i n}}$} & Design & \multicolumn{3}{|c|}{ Experiment } & \multirow{3}{*}{$\frac{G_{S_{-} i n_{-} 50 \%}}{G_{S_{-} i n}}$} \\
\hline & & & $f_{S \_i n \_a v g}$ & $f_{S_{-} i n_{-} 05 \%}$ & \multirow{2}{*}{$\frac{\mathrm{CV}}{\%}$} & & $G_{S_{-} \text {in }}$ & $G_{S \_ \text {in_avg }}$ & $G_{S_{-} i n_{-} 50 \%}$ & \multirow{2}{*}{$\frac{\mathrm{CV}}{\%}$} & \\
\hline & & \multicolumn{3}{|c|}{$\mathrm{N} / \mathrm{mm}^{2}$} & & & \multicolumn{3}{|c|}{$\mathrm{kN} / \mathrm{mm}^{2}$} & & \\
\hline \multirow{5}{*}{ 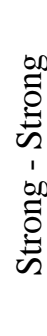 } & 3L3P_LF_S-S & 1.92 & 4.16 & 3.47 & 7.1 & 1.81 & 0.50 & 0.55 & 0.53 & 12.4 & 1.05 \\
\hline & 3L3P_NF_S-S & 1.92 & 4.29 & 3.04 & 12.5 & 1.58 & 0.50 & 0.53 & 0.51 & 7.6 & 1.03 \\
\hline & 5L5P_LF_S-S & 2.30 & 4.50 & 3.83 & 6.3 & 1.66 & 0.50 & 0.62 & 0.59 & 14.1 & 1.18 \\
\hline & 5L5P_NF_S-S & 2.30 & 4.24 & 3.54 & 7.0 & 1.54 & 0.50 & 0.56 & 0.55 & 8.7 & 1.09 \\
\hline & 5L7P_NF_S-S & 1.65 & 4.24 & 3.66 & 5.9 & 2.22 & 0.50 & 0.65 & 0.62 & 13.0 & 1.25 \\
\hline \multirow{5}{*}{ 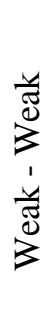 } & 3L3P_LF_W-W & 1.92 & 3.13 & 2.31 & 11.2 & 1.20 & 0.50 & 0.63 & 0.59 & 19.5 & 1.19 \\
\hline & 3L3P_NF_W-W & 1.92 & 2.81 & 1.25 & 23.8 & 0.65 & 0.50 & 0.42 & 0.38 & 36.0 & 0.75 \\
\hline & 5L5PP_LF_W-W & 2.30 & 3.00 & 2.55 & 6.5 & 1.10 & 0.50 & 0.54 & 0.53 & 8.0 & 1.05 \\
\hline & 5L5P_NF_W-W & 2.30 & 3.31 & 2.86 & 5.8 & 1.24 & 0.50 & 0.60 & 0.57 & 16.7 & 1.14 \\
\hline & 5L7P_NF_W-W & 1.65 & 2.69 & 2.43 & 4.1 & 1.48 & 0.50 & 0.81 & 0.78 & 11.5 & 1.56 \\
\hline
\end{tabular}


Table 5 Results of out-of-plane shear

\begin{tabular}{|c|c|c|c|c|c|c|}
\hline \multirow{4}{*}{\multicolumn{2}{|c|}{ Specimen Group Name }} & \multicolumn{5}{|c|}{ Out-of-plane shear strength } \\
\hline & & \multirow{2}{*}{$\begin{array}{l}\# 1324 \\
F_{S_{-} \text {out }}\end{array}$} & \multicolumn{3}{|c|}{ Experiment } & \multirow{4}{*}{$\begin{array}{c}\frac{f_{S_{-} \text {out_05\% }}}{F_{S_{-} \text {out }}} \\
1.87\end{array}$} \\
\hline & & & $f_{S_{-} \text {out_avg }}$ & $f_{S_{-} \text {out } \_05 \%}$ & $\mathrm{CV}$ & \\
\hline & & \multicolumn{3}{|c|}{$\mathrm{N} / \mathrm{mm}^{2}$} & $\%$ & \\
\hline \multirow{5}{*}{ 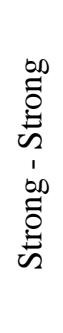 } & 3L3P_LF_S-S & 0.90 & 2.33 & 1.68 & 11.9 & \\
\hline & 3L3P_NF_S-S & 0.90 & 2.29 & 1.88 & 7.7 & 2.09 \\
\hline & 5L5P_LF_S-S & 0.90 & 1.79 & 1.02 & 18.6 & 1.13 \\
\hline & 5L5P_NF_S-S & 0.90 & 1.76 & 1.46 & 7.3 & 1.62 \\
\hline & 5L7P_NF_S-S & 0.90 & 1.69 & 1.41 & 7.2 & 1.56 \\
\hline \multirow{5}{*}{$\begin{array}{l}\frac{y}{0} \\
\sum_{0}^{3} \\
1 \\
\frac{1}{0} \\
3\end{array}$} & 3L3P_LF_W-W & 0.90 & 0.69 & 0.46 & 14.2 & 0.52 \\
\hline & 3L3P_NF_W-W & 0.90 & 0.88 & 0.63 & 12.4 & 0.70 \\
\hline & 5L5PP_LF_W-W & 0.90 & 1.06 & 0.85 & 8.5 & 0.94 \\
\hline & 5L5P_NF_W-W & 0.90 & 1.02 & 0.81 & 8.6 & 0.90 \\
\hline & 5L7P_NF_W-W & 0.90 & 0.60 & 0.45 & 10.5 & 0.50 \\
\hline
\end{tabular}


Table 6 Results of axial compression test

\begin{tabular}{|c|c|c|c|c|c|c|c|c|c|c|c|}
\hline \multirow{4}{*}{\multicolumn{2}{|c|}{$\begin{array}{l}\text { Specimen Group } \\
\text { Name }\end{array}$}} & \multicolumn{5}{|c|}{ Axial compressive strength } & \multicolumn{5}{|c|}{ Axial compressive elasticity } \\
\hline & & \multirow{2}{*}{$\frac{\# 1324}{F_{C}}$} & \multicolumn{3}{|c|}{ Experiment } & \multirow{3}{*}{$\frac{f_{C_{-} 05 \%}}{F_{C}}$} & Design & \multicolumn{3}{|c|}{ Experiment } & \multirow{3}{*}{$\frac{E_{C_{-} 50 \%}}{E_{C}}$} \\
\hline & & & $f_{C_{-} a v g}$ & $f_{C_{-} 05 \%}$ & \multirow{2}{*}{$\frac{\mathrm{CV}}{\%}$} & & $E_{C}$ & $E_{C_{-} a v g}$ & $E_{C_{-} 50 \%}$ & \multirow{2}{*}{$\frac{\mathrm{CV}}{\%}$} & \\
\hline & & \multicolumn{3}{|c|}{$\mathrm{N} / \mathrm{mm}^{2}$} & & & \multicolumn{3}{|c|}{$\mathrm{kN} / \mathrm{mm}^{2}$} & & \\
\hline \multirow{6}{*}{ 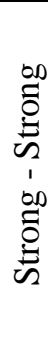 } & 3L3P_LF_S-S & 10.80 & 17.99 & 14.90 & 7.3 & 1.38 & 4.00 & 4.94 & 4.84 & 6.7 & 1.21 \\
\hline & 3L3P_NF_S-S & 10.80 & 18.10 & 16.70 & 3.3 & 1.55 & 4.00 & 4.78 & 4.66 & 8.0 & 1.17 \\
\hline & 3L3P_S_ctl $* 2$ & 10.80 & 24.23 & 21.38 & 5.0 & 1.98 & 4.00 & 5.43 & 5.22 & 13.0 & 1.31 \\
\hline & 5L5P_LF_S-S & 8.10 & 18.12 & 11.94 & 14.6 & 1.47 & 3.00 & 4.66 & 4.59 & 4.7 & 1.53 \\
\hline & 5L5P_NF_S-S & 8.10 & 18.10 & 16.71 & 3.3 & 2.06 & 3.00 & 4.78 & 4.66 & 8.0 & 1.55 \\
\hline & 5L7P_NF_S-S & 10.41 & 20.93 & 17.94 & 6.1 & 1.72 & 3.00 & 5.52 & 5.43 & 5.0 & 1.81 \\
\hline \multirow{6}{*}{ 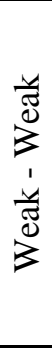 } & 3L3P_LF_W-W & 2.26 & 10.51 & 7.85 & 6.4 & 3.47 & 1.00 & 2.68 & 2.53 & 20.0 & 2.53 \\
\hline & 3L3P_NF_W-W & 2.26 & 10.95 & 9.37 & 6.6 & 4.14 & 1.00 & 2.55 & 2.41 & 19.5 & 2.41 \\
\hline & 3L3P_W_ctl*2 & 2.26 & 13.71 & 11.06 & 8.3 & 4.88 & 1.00 & 2.80 & 2.72 & 10.1 & 2.72 \\
\hline & 5L5P_LF_W-W & 4.68 & 13.45 & 11.76 & 3.9 & 2.51 & 1.20 & 2.62 & 2.56 & 7.3 & 2.14 \\
\hline & 5L5P_NF_W-W & 4.68 & 11.81 & 10.59 & 1.1 & 2.26 & 1.20 & 2.65 & 2.57 & 9.6 & 2.14 \\
\hline & 5L7P_NF_W-W & 3.34 & 8.25 & 7.95 & 8.2 & 2.38 & 0.86 & 1.93 & 1.89 & 7.1 & 2.21 \\
\hline & \multirow{4}{*}{$\begin{array}{c}\text { Real } \\
\text { strength ratio }\end{array}$} & \multicolumn{3}{|c|}{ (3L3P_LF_S-S)/(3L3P_S_ctl) $=$} & 0.74 & \multirow{4}{*}{\multicolumn{2}{|c|}{$\begin{array}{c}\text { Real } \\
\text { stiffness ratio }\end{array}$}} & \multicolumn{3}{|c|}{ (3L3P_LF_S-S)/(3L3P_S_ctl) $=$} & 0.91 \\
\hline & & \multicolumn{3}{|c|}{$($ 3L3P_NF_S-S)/(3L3P_S_ctl) $=$} & 0.75 & & & \multicolumn{3}{|c|}{ (3L3P_NF_S-S)/(3L3P_S_ctl) $=$} & 0.88 \\
\hline & & \multicolumn{3}{|c|}{$\left(3 \mathrm{~L} 3 \mathrm{P} \_L F+W-W\right) /\left(3 \mathrm{~L} 3 \mathrm{P} \_\mathrm{W}\right.$ _ctl $)=$} & 0.77 & & & \multicolumn{3}{|c|}{$($ 3L3P_LF_W-W)/(3L3P_W_ctl) $=$} & 0.96 \\
\hline & & (3L3P_N & $\mathrm{W}) /(3 \mathrm{~L}$ & W_ctl) $=$ & 0.80 & & & \multicolumn{3}{|c|}{ (3L3P_NF_W-W)/(3L3P_W_ctl) $=$} & 0.91 \\
\hline
\end{tabular}




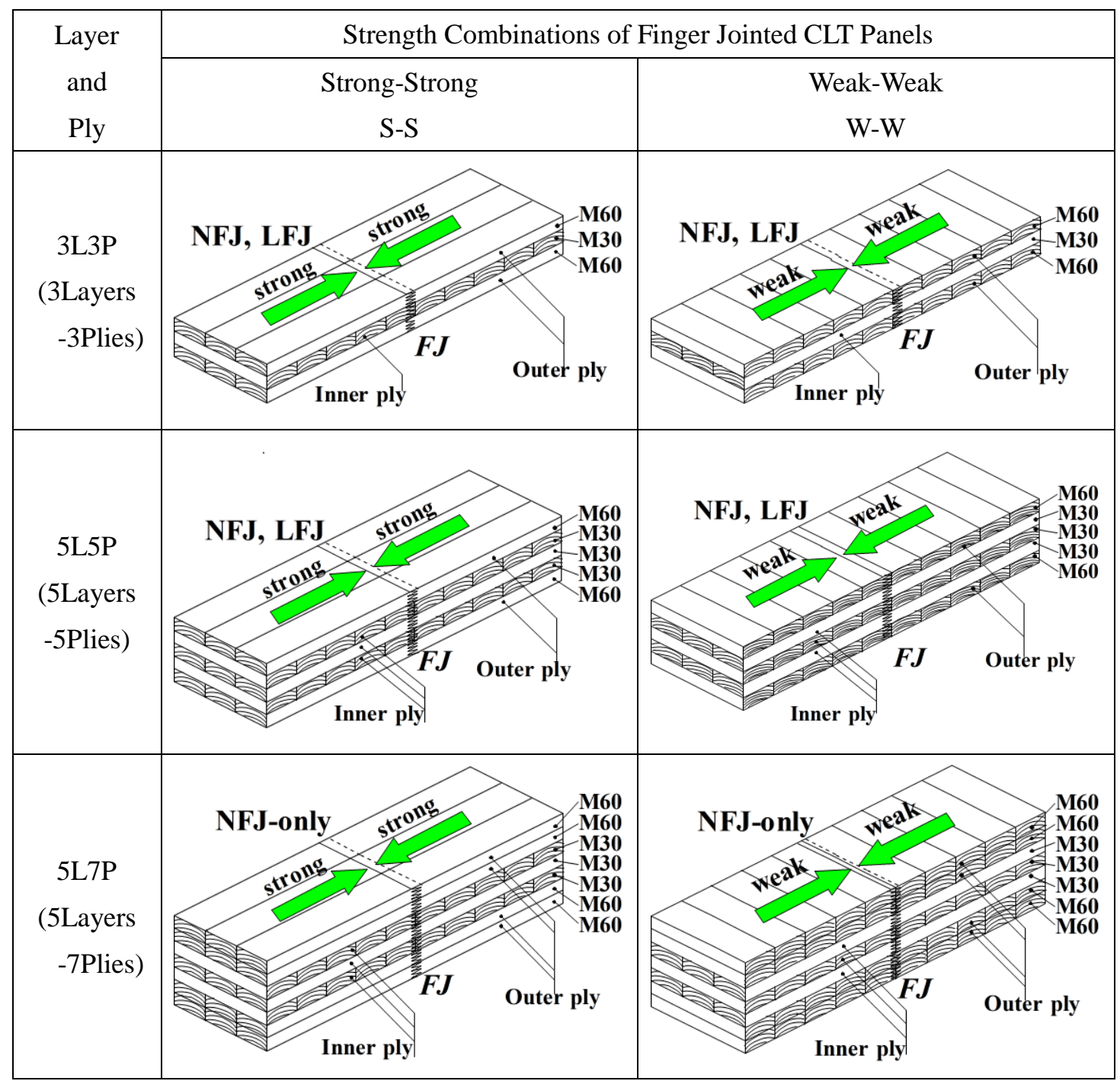

Fig.1 JAS definitions of CLT and descriptions of finger jointed CLT specimens 


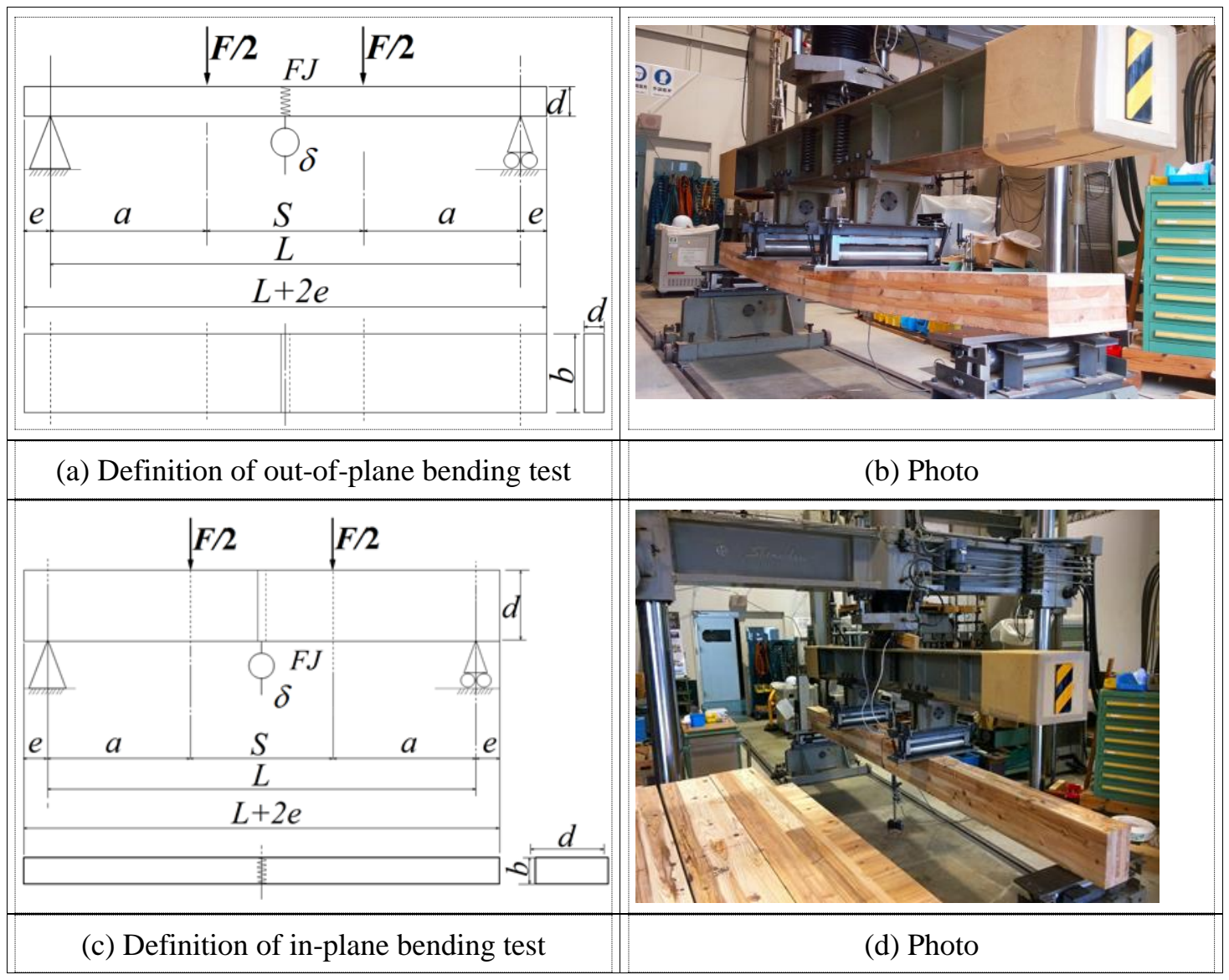

Fig.2 Set-ups for the bending test on the finger jointed CLT specimens 


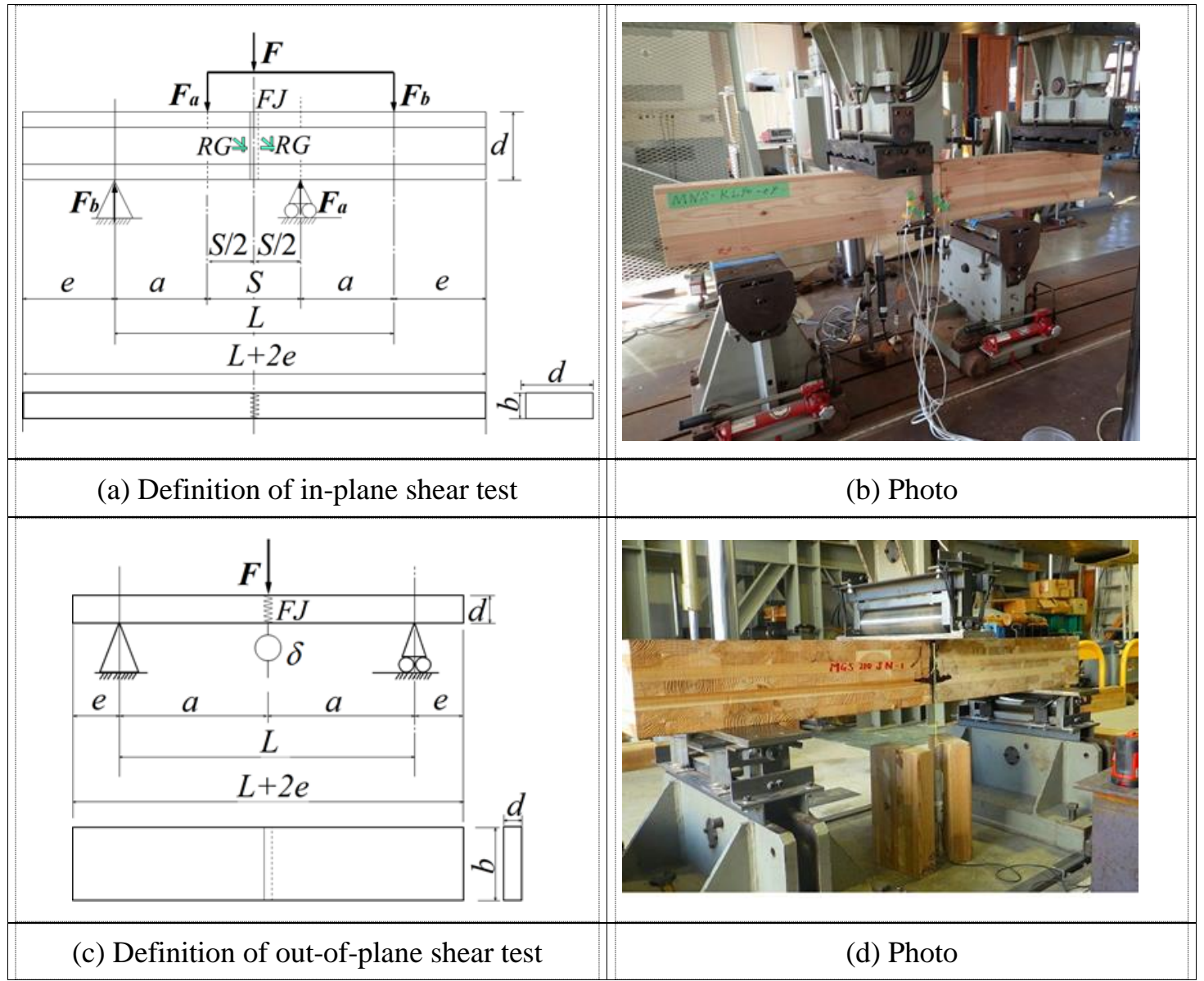

Fig.3 Setups for the shear test on the finger jointed CLT specimens. 


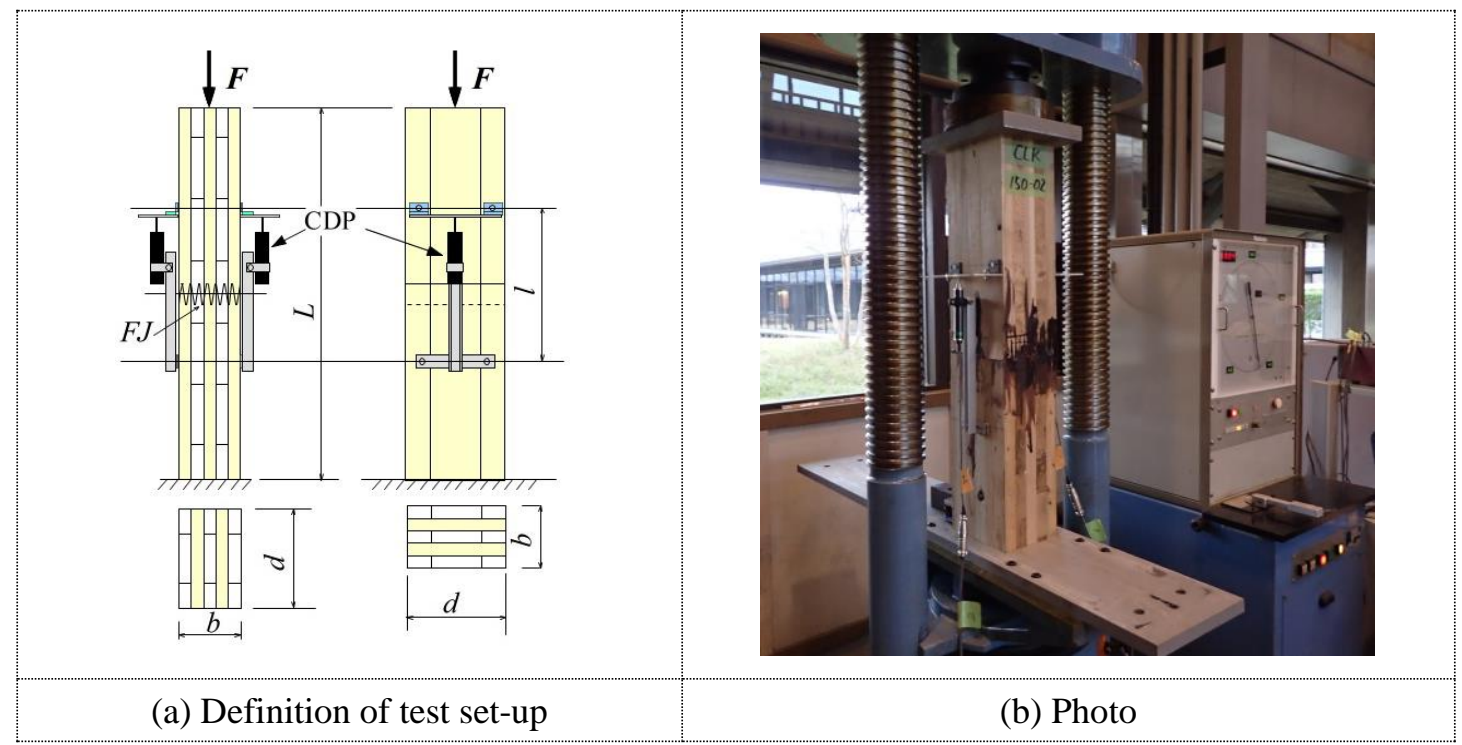

Fig.4 Setup for the compression test on the finger jointed CLT specimens. 


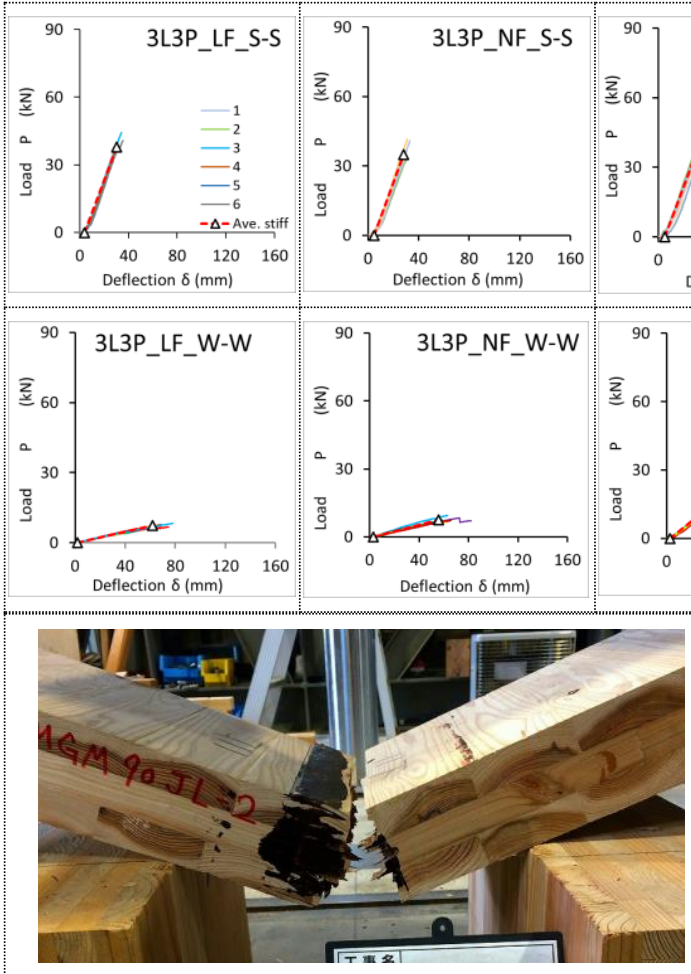

a) Tear-off failure at fingers (3L3P_LF_W-W)

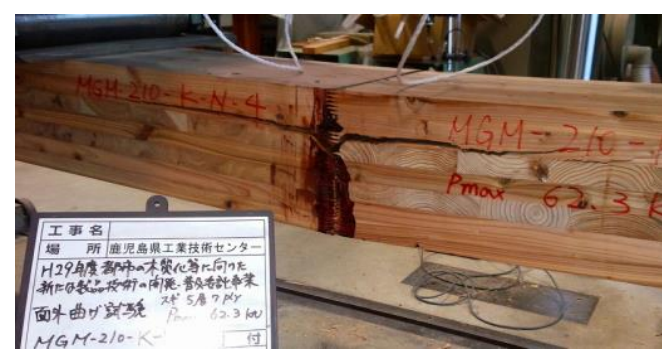

b) Typical bending failure (5L7P_NF_S-S)

Fig.5 $P-\delta$ relationships and typical failure phenomenae of finger jointed CLT specimens subjected to out-of-plane bending moment. 

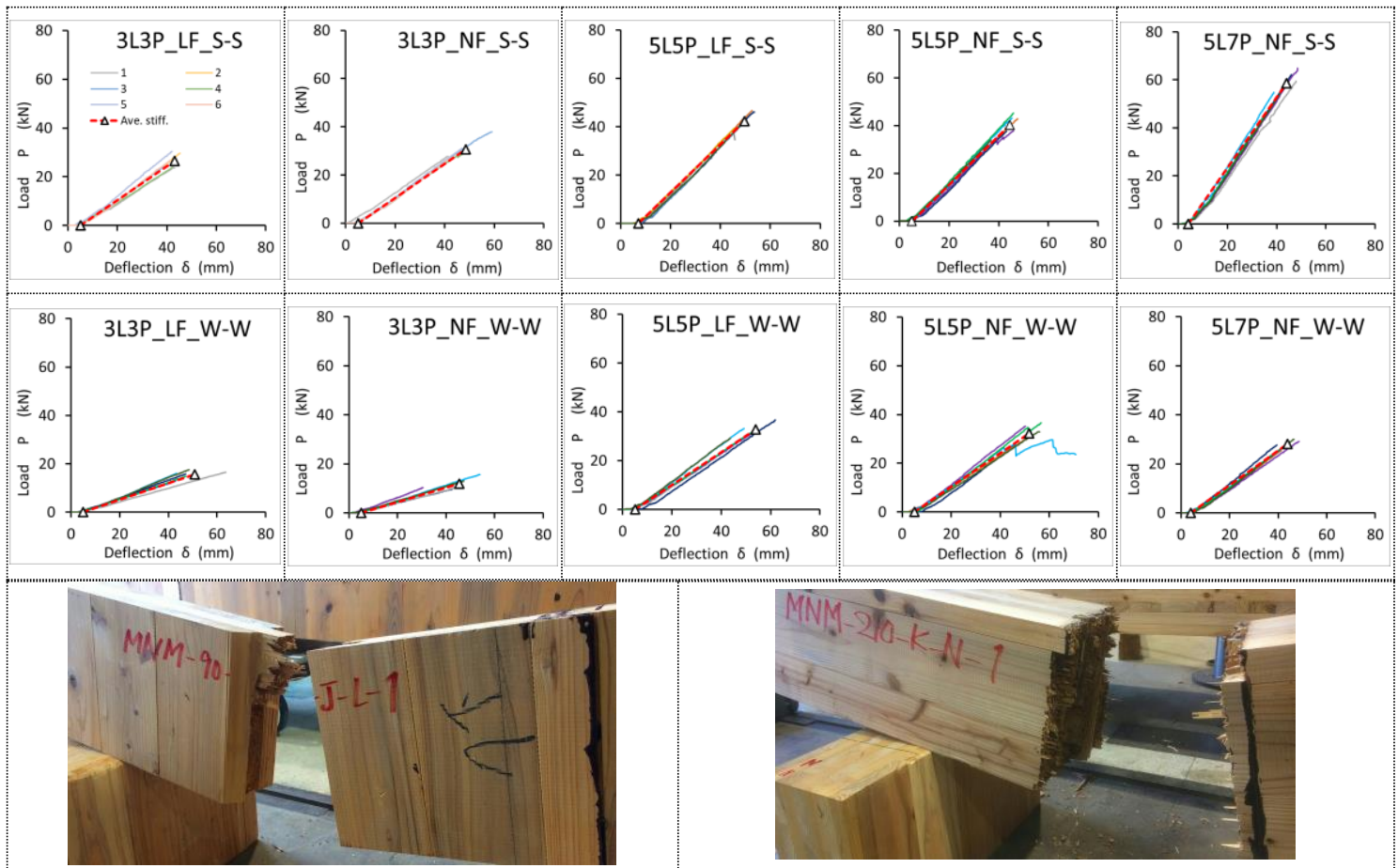

a) Tear-off failure at finger (3L3P_LF_W-W)

b) Tear-off failure at finger (5L7P_NF_S-S)

Fig.6 $P-\delta$ relationships and typical failure phenomenae of finger jointed CLT specimens subjected to in-plane bending moment. 

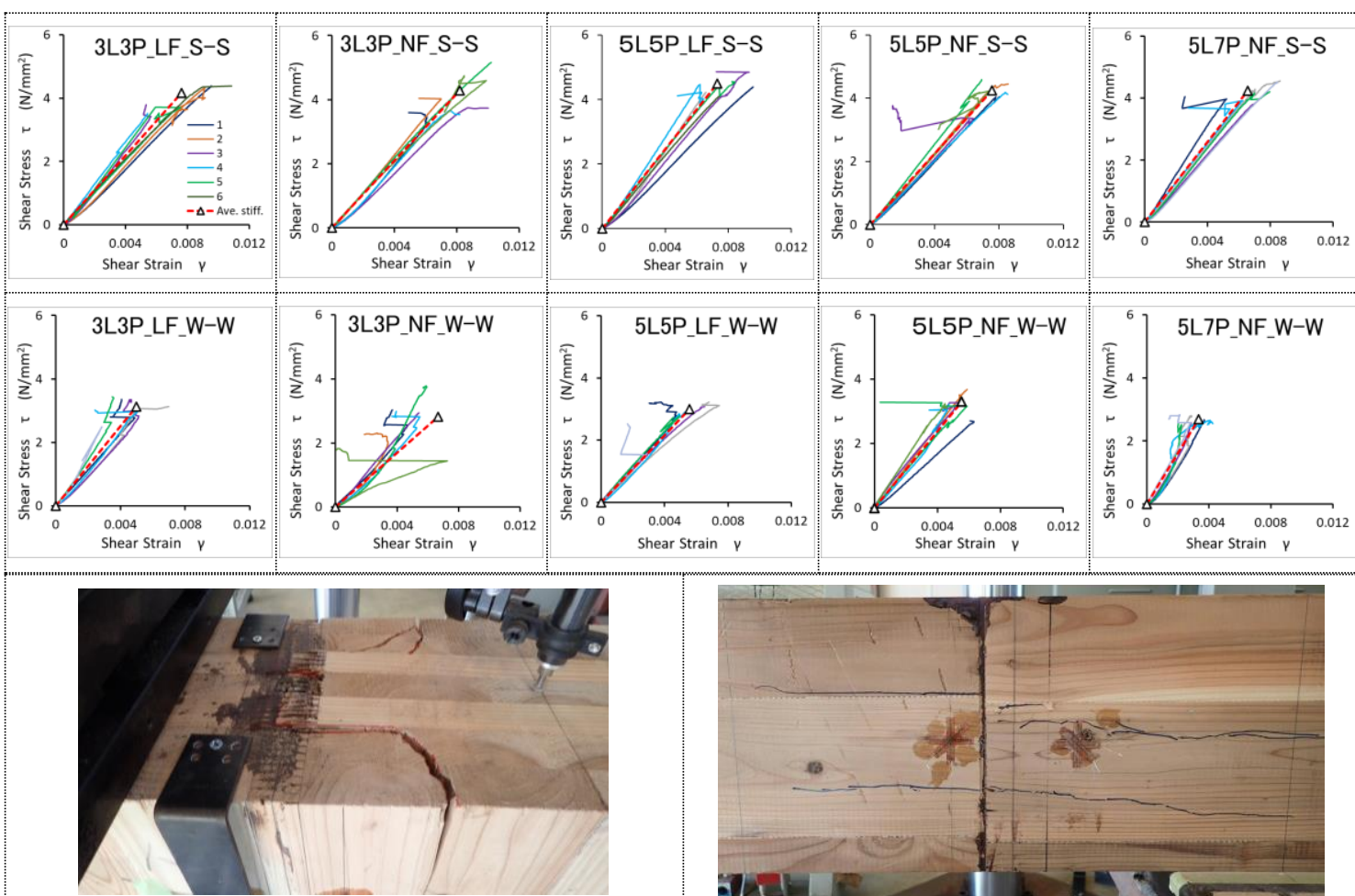

a)Torsional failure mode (5L7P_NF_W-W)

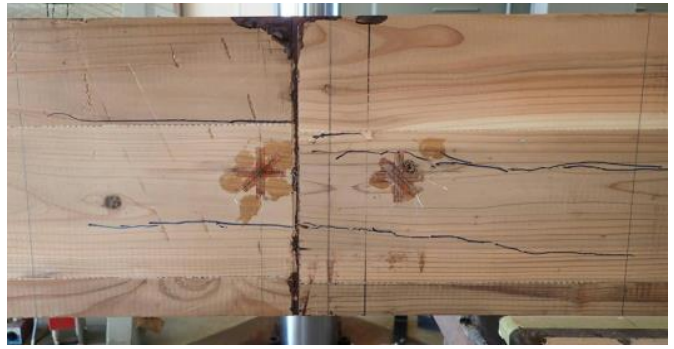

b)Shear failure mode (3L3P_NF_S-S)

Fig.7 $\tau-\gamma$ relationships and typical failure phenomenae of finger jointed CLT specimens subjected to in-plane shear force. 


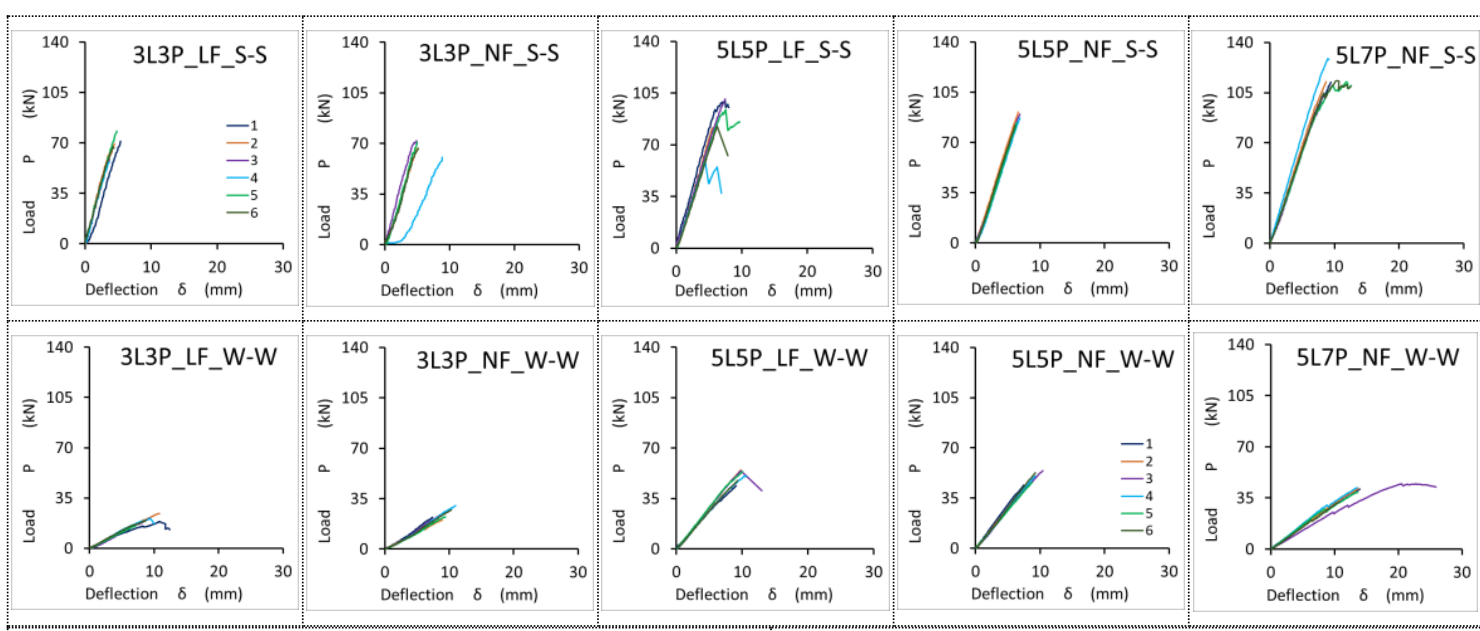

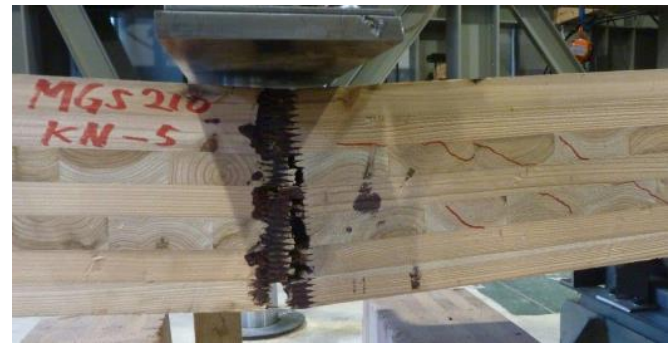

a)Bending with rolling shear failre (5L7P_NF_S-S)

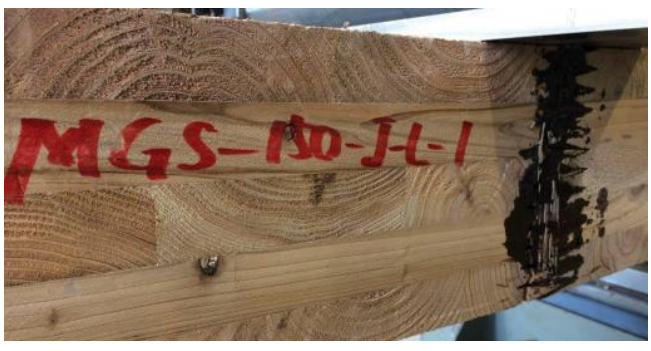

b)Bending failure (5L5P_NF_W-W)

Fig.8 $P-\delta$ relationships and typical failure phenomenae of finger jointed CLT specimens subjected to out-of-plane shear force. 


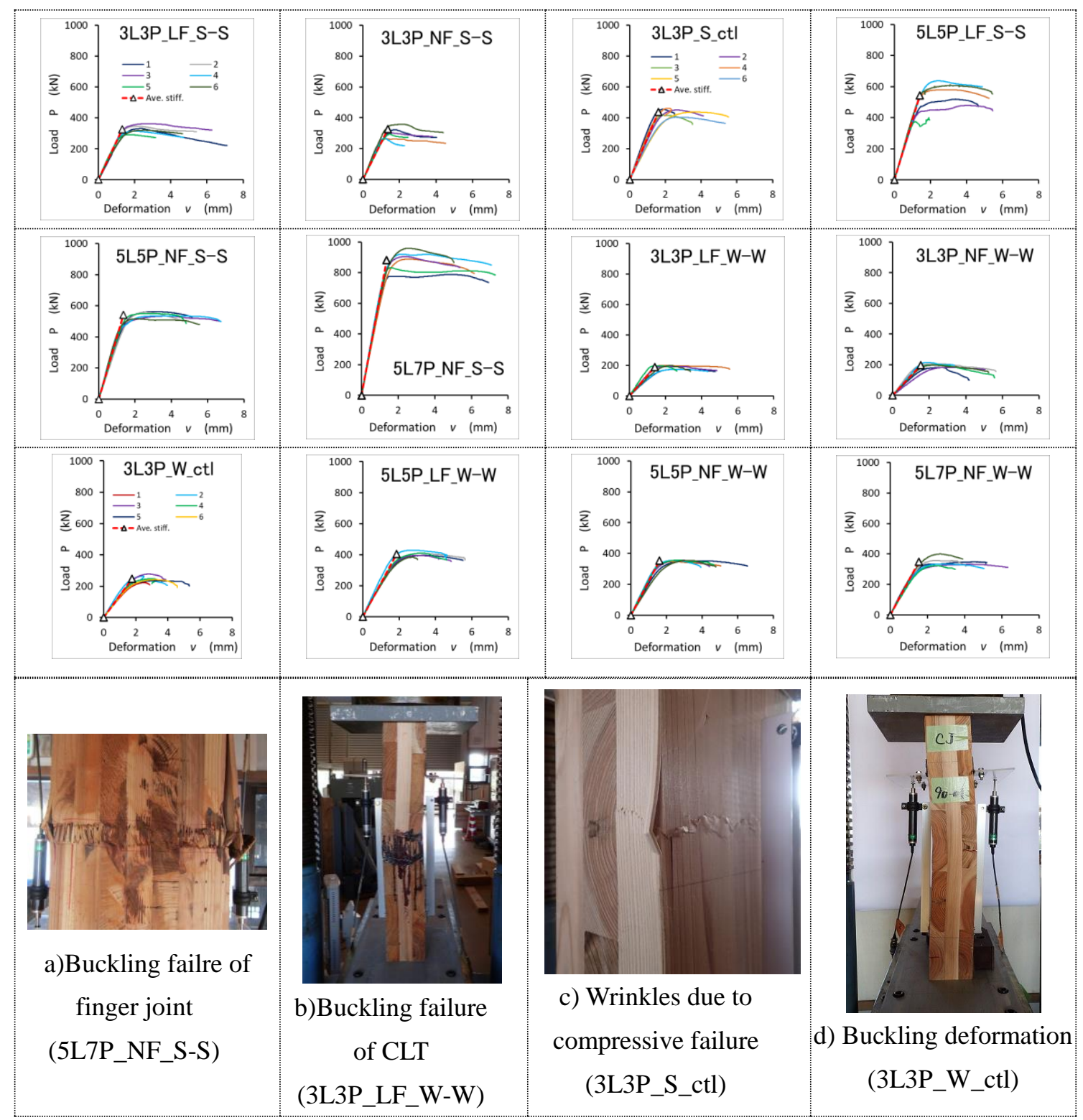

Fig.9 $P$ - $v$ relationships and typical failure phenomenae of finger jointed CLT specimens subjected to compression force. 
Online Resource-1

Article title: Mechanical Performances of Finger Jointed Cross Laminated Timber (CLT)

Journal name: European Journal of Wood and Wood Products

Authors names: Kohei Komatsu, Makoto Nakatani, Toru Nakahara, Kenji Komatsu, Yasunobu Noda Affiliation and E-mail Address of the Corresponding Author: Kohei Komatsu, Research Institute for Sustainable Humanosphere, Kyoto University, Kyoto, Japan. E-mail: kkomatsu@rish.kyoto-u.ac.jp

\section{Observed profiles of CLT cut by two different finger cutters (unit in mm and degree)}

We measured the finger-cutting profiles mainly on the central part of photographic images shown below by using image-editing software. The sample numbers observed were 18 for each finger type.

\begin{tabular}{|c|c|c|c|c|c|c|c|c|c|c|}
\hline & & $\begin{array}{r}\text { Larg } \\
\text { ominal } \mathrm{f}\end{array}$ & $\begin{array}{l}\text { Finger: } \\
\text { ger leng }\end{array}$ & $\begin{array}{l}\mathrm{F} \\
\mathrm{i}: 5 \mathrm{~mm}\end{array}$ & & & $\begin{array}{l}\text { Norn } \\
\text { ominal }\end{array}$ & $\begin{array}{l}\text { Finger } \\
\text { ger lens }\end{array}$ & $\begin{array}{l}\mathrm{NF} \\
: 24 \mathrm{mn}\end{array}$ & \\
\hline $\begin{array}{l}\text { Photo } \\
\text { image }\end{array}$ & & & & $\begin{array}{l}= \\
=\end{array}$ & & of & 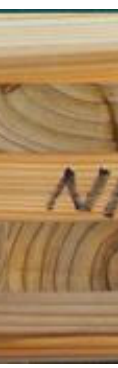 & $\overline{\bar{E}}$ & 2 & 目 \\
\hline & $l$ & $b_{b}$ & $b_{t}$ & $p$ & $\theta$ & $l$ & $b_{b}$ & $b_{t}$ & $p$ & $\theta$ \\
\hline Mean & 50.98 & 1.51 & 2.27 & 11.96 & 4.59 & 24.33 & 0.87 & 1.59 & 5.95 & 4.10 \\
\hline s.d & 0.259 & 0.089 & 0.188 & 0.119 & 0.157 & 0.165 & 0.074 & 0.153 & 0.060 & 0.207 \\
\hline $\mathrm{CV}(\%)$ & 0.5 & 5.9 & 8.3 & 1.0 & 3.4 & 0.7 & 8.5 & 9.6 & 1.0 & 5.0 \\
\hline $\begin{array}{r}\text { Defin } \\
\text { fin } \\
\text { pro }\end{array}$ & $n$ of & & $\frac{b_{b} \downarrow}{p}<$ & 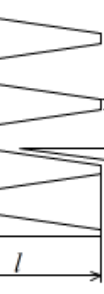 & $\frac{\overline{\overline{1}}}{T^{\theta}}$ & & $\begin{array}{l}l: \text { Leng } \\
b_{b}: \text { Bott } \\
b_{t}: \text { Top } \\
p: \text { Fing } \\
\theta: \text { Scarf }\end{array}$ & $\begin{array}{l}\text { of fin } \\
n \text { width } \\
\text { idth of } f \\
\text { pitch } \\
\text { ngle (ca }\end{array}$ & $\begin{array}{l}\text { er } \\
\text { f finger } \\
\text { ger } \\
\text { ulated ) }\end{array}$ & \\
\hline
\end{tabular}


Online Resource-2

Article title: Mechanical Performances of Finger Jointed Cross Laminated Timber (CLT)

Journal name: European Journal of Wood and Wood Products

Authors names: Kohei Komatsu, Makoto Nakatani, Toru Nakahara, Kenji Komatsu, Yasunobu Noda Affiliation and E-mail Address of the Corresponding Author: Kohei Komatsu, Research Institute for Sustainable Humanosphere, Kyoto University, Kyoto, Japan. E-mail: kkomatsu@rish.kyoto-u.ac.jp

\section{Determination of the appropriate push-in pressure}

In Japan, the push-in pressure given to the industrial use finger joint has been determined empirically. The Fig.1-(a) to (d) explain how the push-in pressure was determined.

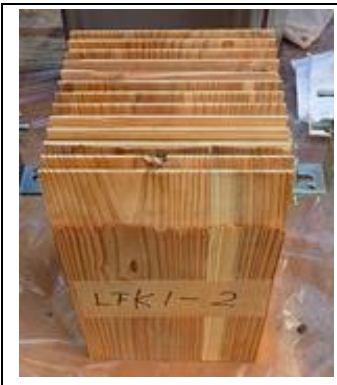

(a) Half specimen

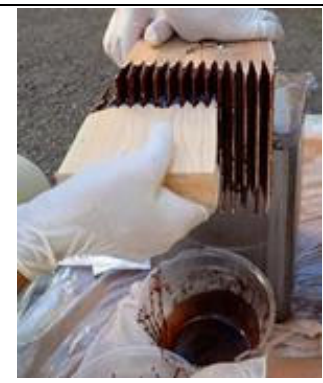

(b) Glue pasting

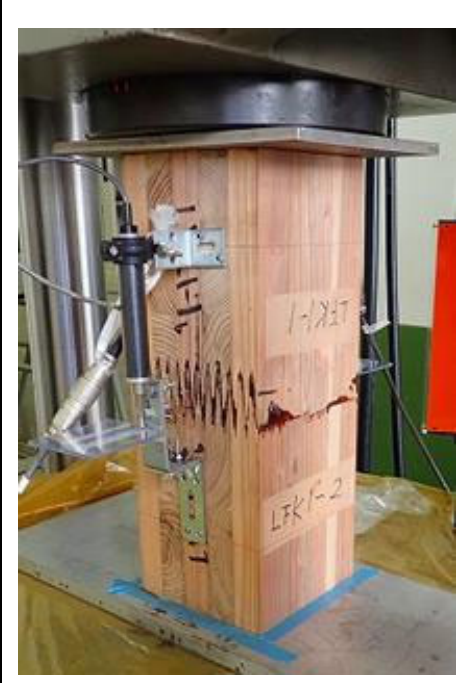

(c) Push-in test on the precured finger jointed specimen for getting stressdeformation curve

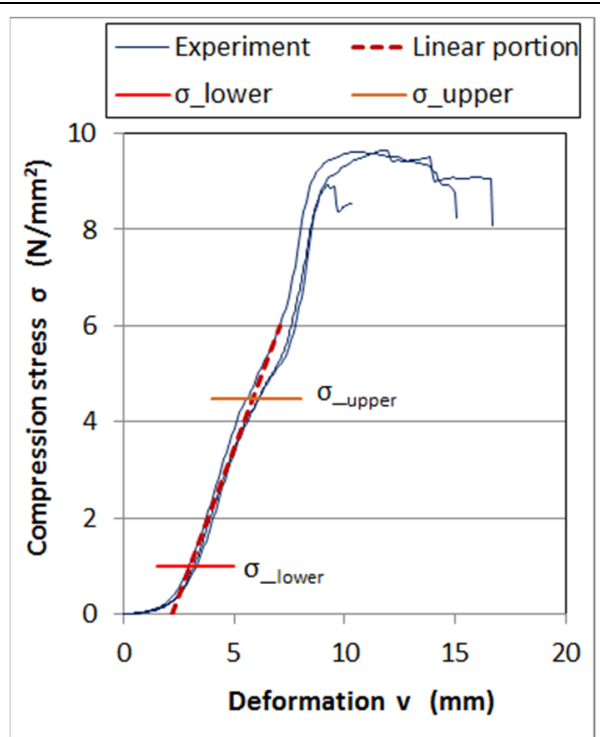

(d) Image of stress-deformation curve and determination of lower limit stress

Fig.1 Procedure for determining the appropriate push-in pressure of finger joint

At first, a push-in test was executed on a pair of the pre-cured finger jointed specimen. Next, we visually determined the lower limit stress $\sigma_{\text {lower }}$ and the upper limit stress $\sigma_{\text {upper }}$ within the linear portion of measured stress-deformation curve. Finally, an appropriate push-in pressure was determined from the stress closer to the lower limit stress. The reason why stress closer to the lower limit value was selected was that when the stress was excessively large, some damage might occur at valley part of finger cut timber, and conversely, if the stress was too low, there might be a risk of insufficient clamping pressure to the adhesion surface. In addition, considering the manufacturing process having large cross section or/and on-site finger jointing cases, it was often difficult to apply higher pressure, consequently stress closer to the lower limit value of the linear stress-deformation portion has been practically adopted as an appropriate push-in pressure, especially in the case of on-site finger joint. In this study, standing on the same principle mentioned above, the appropriate push-in pressure for manufacturing finger jointed CLT-CLT specimens was determined through the push-in tests using 
CLT blocks whose dimension is $150 \mathrm{~mm} \times 150 \mathrm{~mm} \times 275 \mathrm{~mm}$. The push-in tests were carried out on both the large finger joint and the normal finger joint by mixing the curing agent with the resorcinol resin adhesive for simulating the actual adhesion condition. The amount of pasted adhesive was $250 \mathrm{~g} / \mathrm{m}^{2}$ for the total adhesion area. The push-in tests were done on the universal testing machine with a test speed of $2 \mathrm{~mm} / \mathrm{min}$. Replications of specimens with the same combination of finger joint were six.

Figs. 2 -(a) to (d) show stress ( $\sigma$ )-deformation (v) relationships of pre-cured finger jointed specimens and the estimated lower limit stress as the appropriate push-in pressure value.

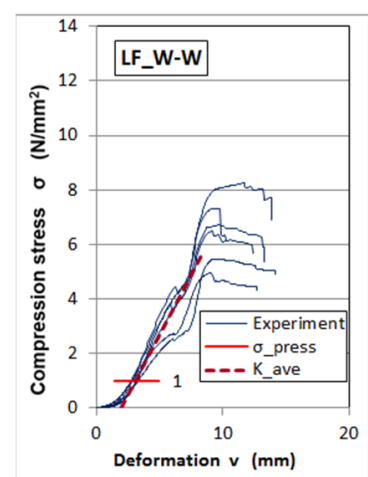

(a) LF_W-W

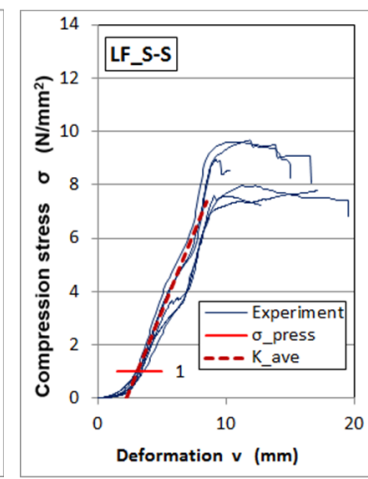

(b) LF_S-S

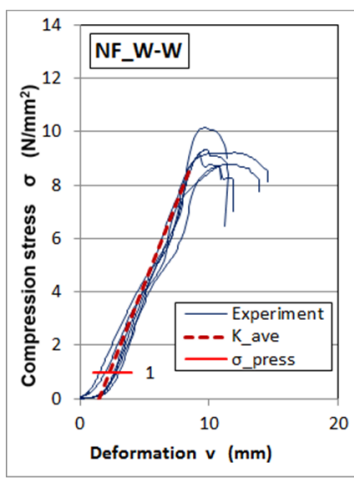

(c) NF_W-W

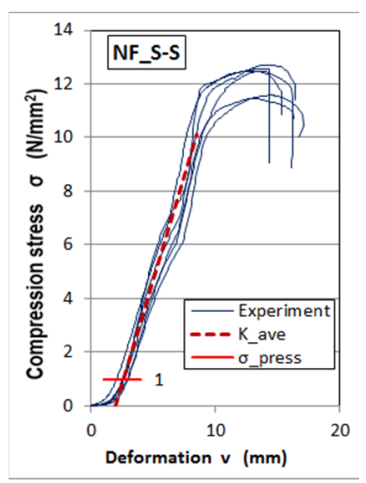

(d) NF_S-S

Fig.2 Stress-deformation relationships of pre-cured finger jointed CLT-CLT specimen

From these experimental results, by paying attentions to the possibilities of the on-site finger jointing condition, we decided that $1 \mathrm{~N} / \mathrm{mm}^{2}$ was the appropriate value as the push-in pressure which was to be used commonly for producing all finger jointed CLT-CLT specimens to be used in this study. 
Online Resource-3

Article title: Mechanical Performances of Finger Jointed Cross Laminated Timber (CLT)

Journal name: European Journal of Wood and Wood Products

Authors names: Kohei Komatsu, Makoto Nakatani, Toru Nakahara, Kenji Komatsu, Yasunobu Noda Affiliation and E-mail Address of the Corresponding Author: Kohei Komatsu, Research Institute for Sustainable Humanosphere, Kyoto University, Kyoto, Japan. E-mail: kkomatsu@rish.kyoto-u.ac.jp

\section{Finger cutting and specimen production}

Finger cutting was performed using an existing finger cutting machine equipped with a function capable of cutting $50 \mathrm{~mm}$ large fingers to be used in this study and large size test specimens with a width of $1 \mathrm{~m}$. Figs. 1- (a) and (b) show situations in which a $1 \mathrm{~m}$ wide laterally glued ply is cut using a $50 \mathrm{~mm}$ finger cutter.

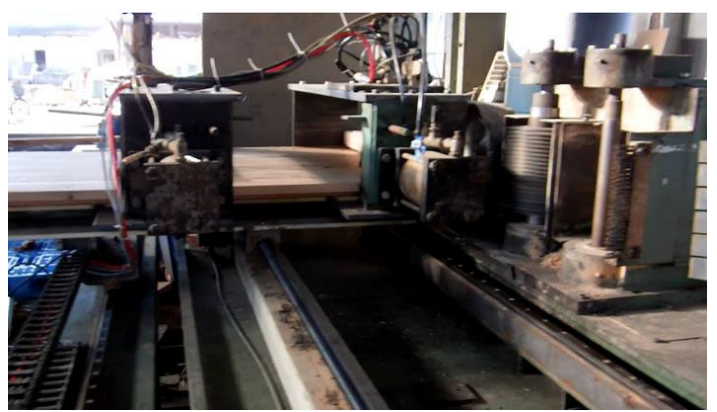

(a) Viewed from lateral side

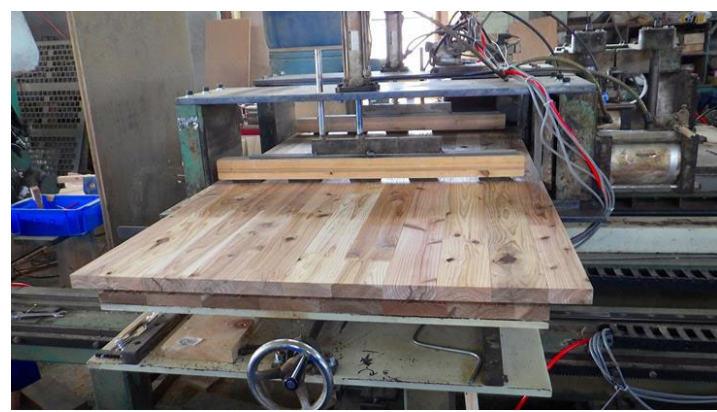

(b) Viewed from specimen side

Fig. 1 Finger cutting situation

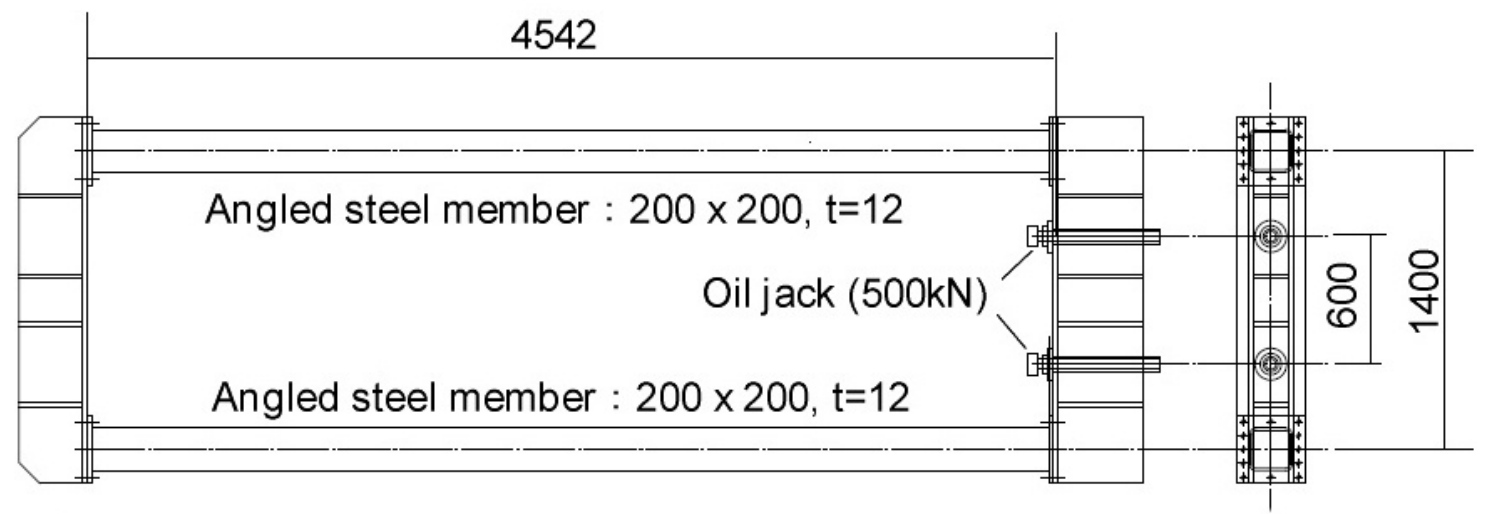

Fig.2 Prototype finger jointing device

Finger joining was executed, with on-site jointing in mind, using simply made temporary pressing device shown in Fig. 2. The temporary pressing device was equipped with two oil jacks (RIKEN D5$500 \mathrm{VC}$ ) with a maximum compression force of $500 \mathrm{kN}$, and can be finger-jointed with a maximum compression force of $1000 \mathrm{kN}$. Fig. 3 shows a situation in which a few test specimens are jointed at one time by the temporary pressing device. 


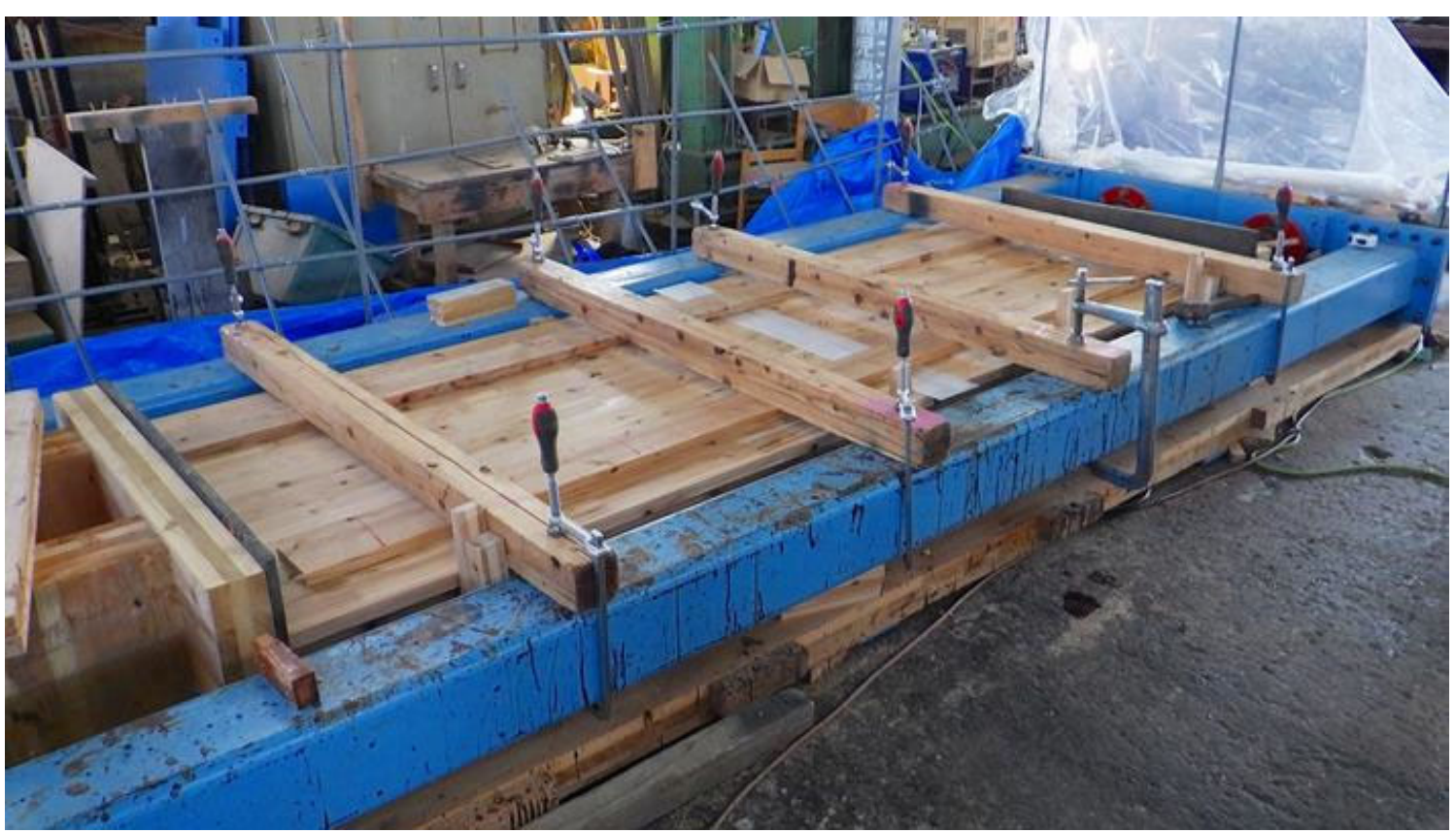

図 3 Fig.3 Situation of jointing a few test specimens in the prototype device 
Online Resource-4

Article title: Mechanical Performances of Finger Jointed Cross Laminated Timber (CLT)

Journal name: European Journal of Wood and Wood Products

Authors names: Kohei Komatsu, Makoto Nakatani, Toru Nakahara, Kenji Komatsu, Yasunobu Noda Affiliation and E-mail Address of the Corresponding Author: Kohei Komatsu, Research Institute for Sustainable Humanosphere, Kyoto University, Kyoto, Japan. E-mail: kkomatsu@rish.kyoto-u.ac.jp

\section{Derivations of the reduction factors of the shear force in the case of the $S=a=1.5 d$ anti-symmetrical four-point bending shear test}

Figure 1 shows the bending moment and shear force diagrams of the anti-symmetrical four-point loading shear test specimen.

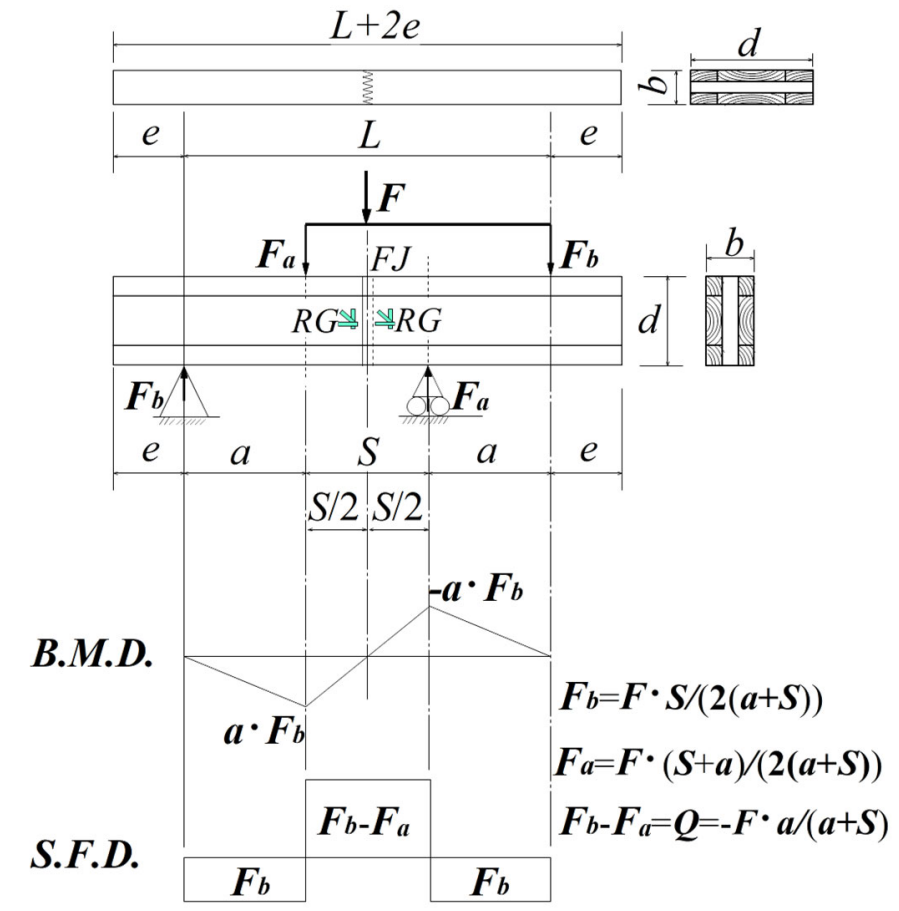

Fig.1 B.M.D. and S.F.D. of the anti-symmetrical four-point loading shear test specimen.

In the Japanese domestic testing manual (Japan HOWTEC, 2011), $S=a=3 d$ is recommended for the GLT and the structural solid sawn timber. In the case of finger jointed CLT panels, however, transversal layers do not resist against bending moment, therefore, the possibility of preceding bending failure becomes higher than GLT or solid-sawn timber, especially in the case of weak-weak finger jointed CLT specimens. After simulations of bending failure and shear failure as the function of $S / d$ or/and $a / d$, we got a foresight that by making $S / d=a / d=1.5$, the possibility of bending failure might be avoided. Hence, the in-plane shear tests on the all CLT specimens finger jointed in weak-weak direction were done by setting $S / d=a / d=1.5$.

New fact, however, that due to "too close" distance between upper loading plate and lower supporting plate, diagonal force transmissions were confirmed in Weak-Weak finger jointed specimen 
as shown in Fig. 2 by assuming that the compressive force perpendicular to the grain shall expand within 45 degrees opened region through the transversal layers.

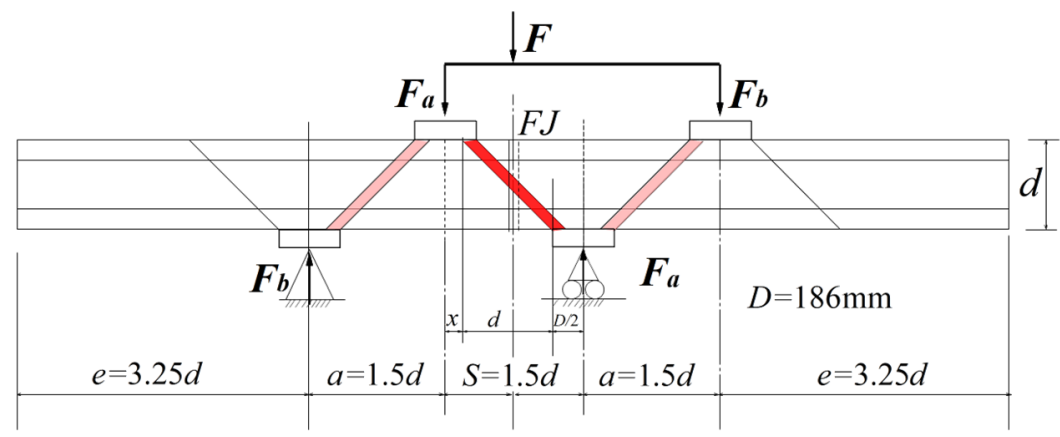

Fig.2 Diagonal force transmission regions (colored parts) in the case of $S / d=a / d=1.5$

From the relationship of $1.5 d=x+d+D / 2$, the value $x$ was determined numerically in each layup, thus the gloss contact area $A_{0}$, diagonal force transmitted area $A_{1}$ and the effective contact area $A_{\mathrm{ef}}=A_{0}-A_{1}$, and the reduction factor of the shear force $\phi$ are calculated as follows;

1) $3 \mathrm{P} 3 \mathrm{~L} \_W-W$

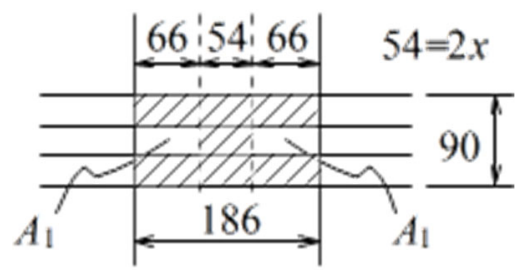

$$
\begin{array}{r}
A_{0}=186 \times 90=16740 \mathrm{~mm}^{2} \\
A_{1}=(66 \times 30) \times 2=3960 \mathrm{~mm}^{2} \\
A_{e f}=A_{0}-A_{1}=12780 \mathrm{~mm}^{2} \\
\phi=\frac{A_{e f}}{A_{0}}=\frac{12780}{16740}=0.763
\end{array}
$$

2) $5 \mathrm{P} 5 \mathrm{~L} \_\mathrm{W}-\mathrm{W}$

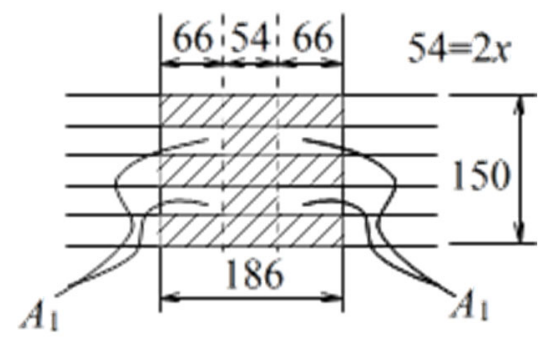

$$
\begin{array}{r}
A_{0}=186 \times 150=27900 \mathrm{~mm}^{2} \\
A_{1}=(66 \times 30) \times 4=7920 \mathrm{~mm}^{2} \\
A_{e f}=A_{0}-A_{1}=19980 \mathrm{~mm}^{2} \\
\phi=\frac{A_{e f}}{A_{0}}=\frac{19980}{27900}=0.716
\end{array}
$$

3) $5 \mathrm{~L} 7 \mathrm{P} \_\mathrm{W}-\mathrm{W}$

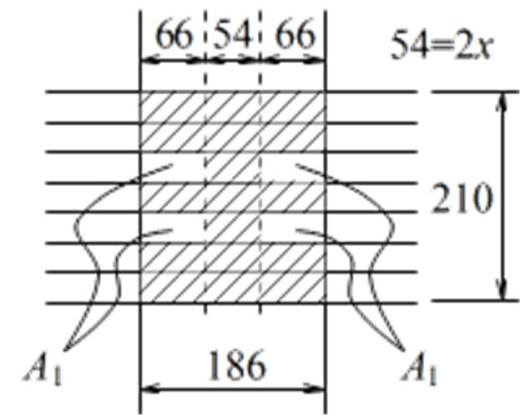

$$
\begin{array}{r}
A_{0}=186 \times 210=39060 \mathrm{~mm}^{2} \\
A_{1}=(66 \times 30) \times 4=7920 \mathrm{~mm}^{2} \\
A_{e f}=A_{0}-A_{1}=31140 \mathrm{~mm}^{2} \\
\phi=\frac{A_{e f}}{A_{0}}=\frac{31140}{39060}=0.797
\end{array}
$$

